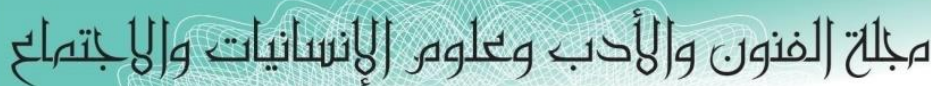

Journal of Arts, Literature, Humanities and Social Sciences

ISSN online: 2414 - 3383

ISSN print: 2616 - 3810

العدد (42) ايلول - سبتهبر 2019

\title{
الترويج وعلافته بالتكرار في الاعلان التلفزيوني
}

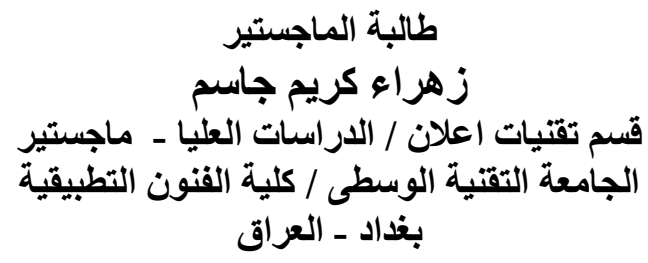

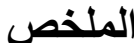

تناول هذا البحث دور التكرار وأثره في أحداث الترويج الاعلاني من خلال الاعلانات التلفزيونية وفاعليته على المشاهد ، فقد تم تقسيم هذا البحث الى ثلاثة فصول الاول الذي يمثل الإطار المنهجي ، و الفصل الثاني الذي يمثل الإطار النظري قسم الى ثلاثة مباحث الاول تناول الترويج الاعلاني من حيث المفهوم والوظائف ، واساليب الترويج المتبعة في الرسالة الاعلانية والعوامل المساعد في إحداث الاثر الترويجي ، أما المبحث الثاني فقد تناول التكر ار من حيث المفهوم والانواع و الوظائف ، و المبحث الثالث الذي تضمن العلاقة الر ابطه بين الترويج و التكر ار و آليات عرض الاعلان الناجح ، و الفصل الثالث الذي تضمن إجراءات البحث و الذي اتبع فيه المنهج الوصفي لتحليل العينة بناءاً على استمارة تحليل استخلصت من مؤشرات الإطار النظري ، والفصل الربع هو

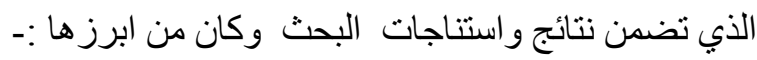
1. أن تكر ار الإعلان لا يؤثر فى زيادة طلب المتلقي على المنتج المعلن عنه و بالتالى فإعادة تكرار الإعلان لمر ات كثثرة لا يفيد فى جذب إنتباه المتلقي و و بإنما يلعب دور اتذكيريا فقط . 2. زيادة عدد مرات تكرار الإعلان قد تؤدى إلى إنخفاض فعالية الإعلان و تدهور عمليات الانتباه و التذكر

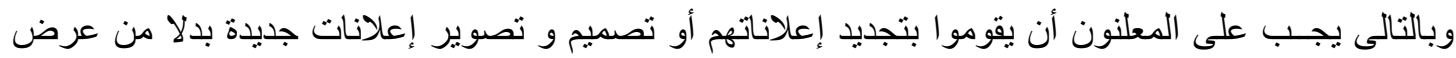
نفس الإعلانات لفتر ات طويلة 3. تسخير تقنيات التصوير و الصوت لإثارة الاهتمام بالموديل الظاهر في الترويج الاعلاني . 


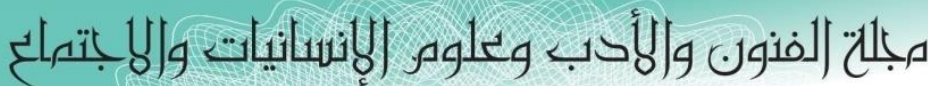

Journal of Arts, Literature, Humanities and Social Sciences

ISSN online: 2414 - 3383

ISSN print: 2616 - 3810

أيلول - سبتمبر 2019

(42) العدد)

\title{
Promotion and Its Relationship to Repetition in Television Advertising
}

\begin{abstract}
This role of repetition and its impact on advertising events through television commercials and effectiveness on the Viewer, this research has been divided into three chapters I, which represents the methodological framework, the second chapter that represents the theoretical framework section to the first three chapters deal with advertising In concept, functions, methods of promotion in advertising and communication Assistant factors effecting promotional impact, either the second topic dealt with repetition in terms of concept and types and functions, and the third section, which included the relationship between China and repetition ad mechanisms Successful third quarter which included search procedures which follow in the descriptive sample analysis based on analysis drawn from indicators form the conceptual framework, chapter 15 is wastages which contained the results of research and was notably:-
\end{abstract}

1. To repeat the Declaration does not affect the receiver's request to increase the advertised product and then repeat the Declaration of many times doesn't help attract the attention of the recipient and Panama plays a reminder only.

2. Increase the frequency of advertising may lead to reduced effectiveness.

3. Harness photographic techniques and sound to arouse interest in the model shown in advertising. 


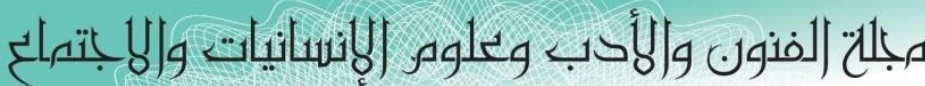

Journal of Arts, Literature, Humanities and Social Sciences

ISSN online: 2414 - 3383

ISSN print: 2616 - 3810

\section{العدد (42) أيلول - سبتمبر 2019}

\section{الفصل الأول}

اولاً: مشكلة البحث

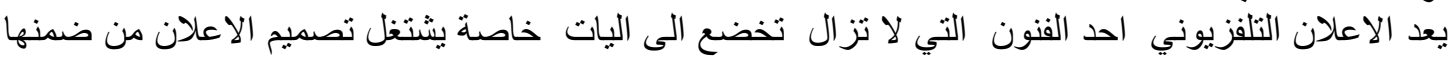

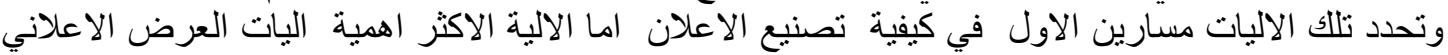

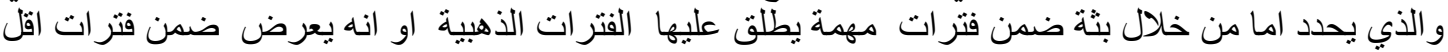

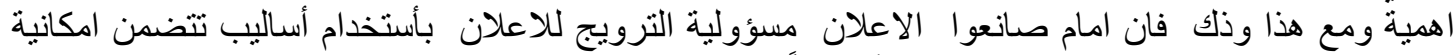

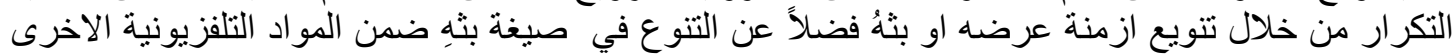

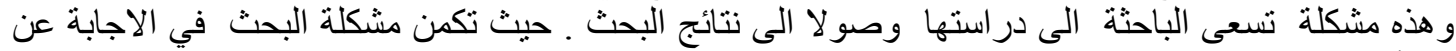

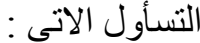
هل ان تكرار البث للاعلان التفزيوني باوقات مختلفة محقق للترويج بشكله المناسب ام لا ؟ يثانياً : هدف البحثث البحث الكثف عن أهمية الترويج و علاقته بالتكر ار في الاعلان التلفزيوني. ثالثاً: الهمية البحث تكمن اهية البحث الحالي في : الهئ

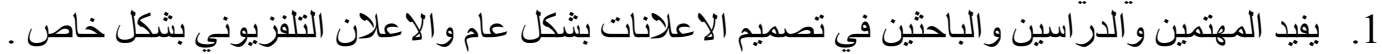

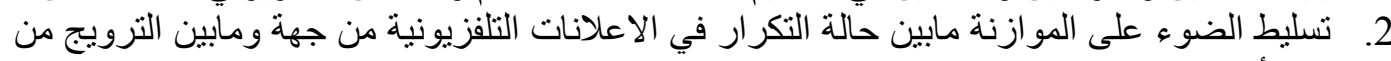

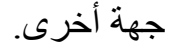
3. يعد الاعلان وسيلة اتصال مهمة تستخدامهُ المؤسسات المتنوعة لإقامة علاقات تبادلية بين المعلن و المتلقي من خلال وسائل اتصال مختلفة الألة

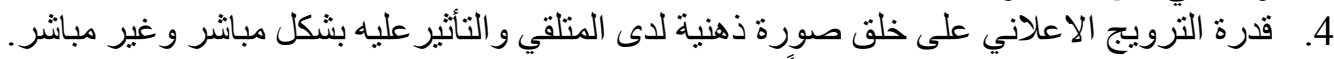

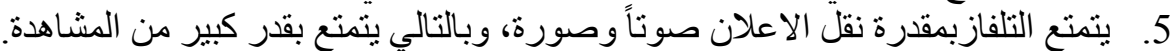
6. تسليط الضوء على أنو اع التكرار المعتمدة في عرض الاعلانات التات التلفزيونية.

$$
\begin{aligned}
& \text { رابعاً : حدود البحث } \\
& \text { 1. الحد الموضو البحي : الترويج و علاقته بالتكر ار في الاعلان التلفزيوني . }
\end{aligned}
$$

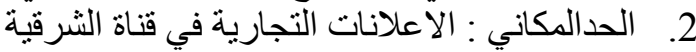

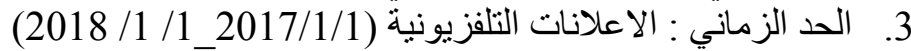

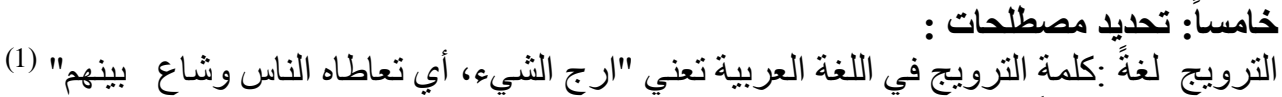

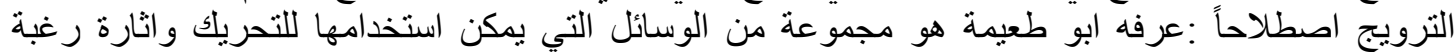

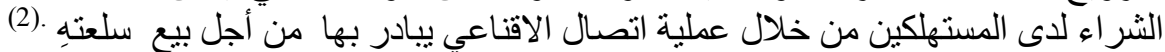

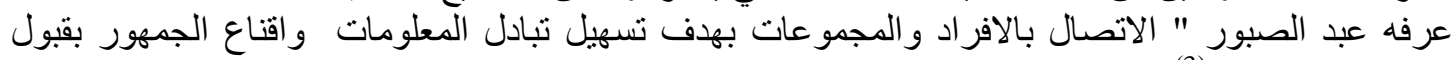

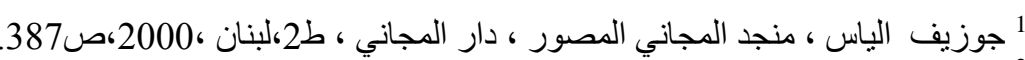

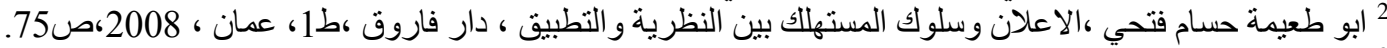
3 عبد الصبور محسن فنحي ، اسرار الترويج في عصر العولمة ، مجموعة النيل العربية ، ط1، القاهرة ، 2000،صاندان 


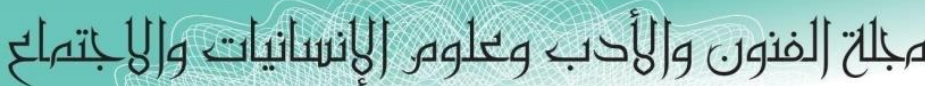

Journal of Arts, Literature, Humanities and Social Sciences

ISSN online: 2414 - 3383

ISSN print: 2616 - 3810

\section{العدد (42) أيلول -سبتمبر 2019}

وتعرفه الباحثة اجر ائبا و هو عملية اتصال تهدف الى اقناع المستهلك بشر اء السلع و الخدمات وتعريفه و وتبيان

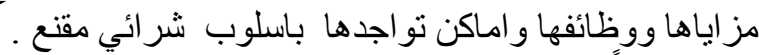



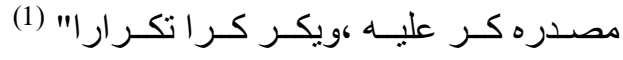

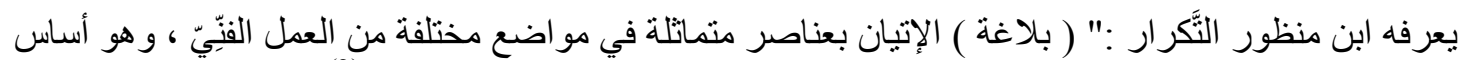
الإيقاع بجميع صوره ، فنجده في الموسيقى كما نجده أساسًا لنظريَّة القافية في مي الثبِّعر " (2).

اصطلاحاً

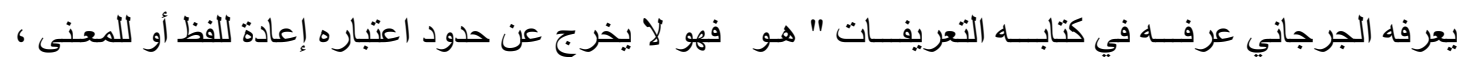

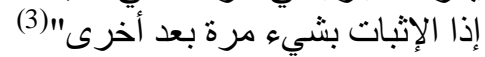

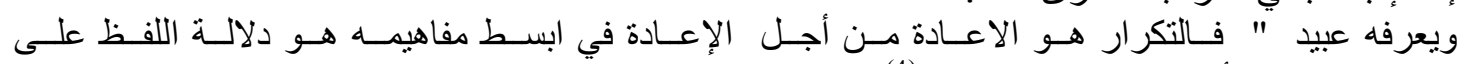

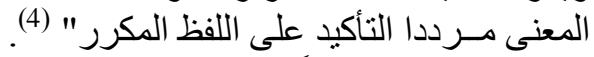
وتعرفه الباحثة اجر ائياً

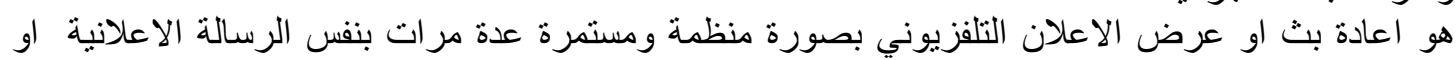

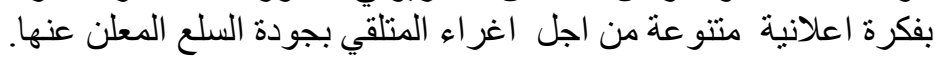
الاعلان التلفزيوني

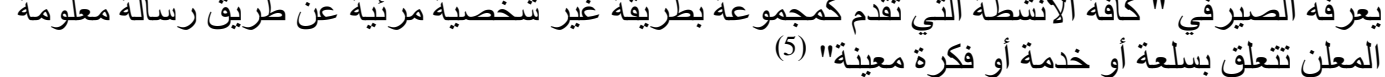

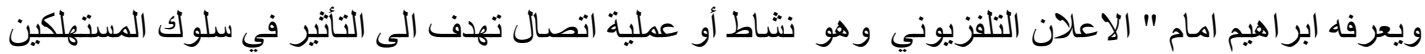

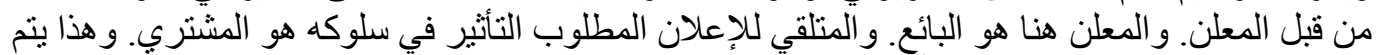

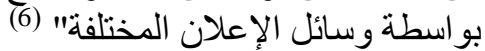

تعرفه الباحثة اجر ائياً

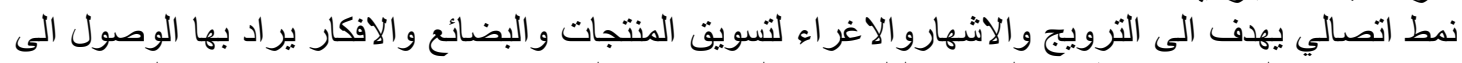

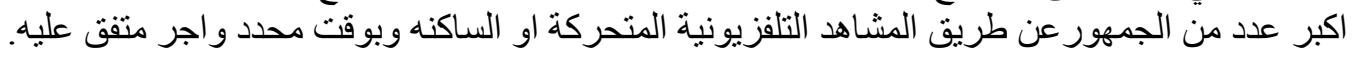

\section{الفصل الثاني \\ الإطار النظري}

المبحث الأول : الترويج الاعلاني

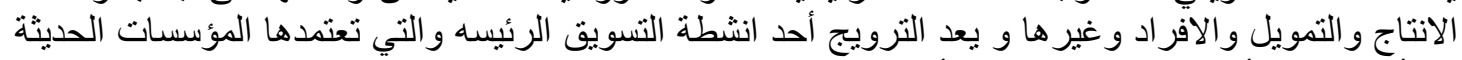

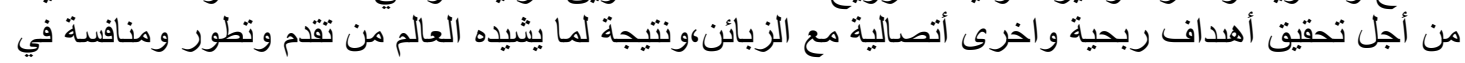

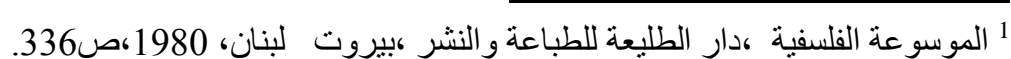

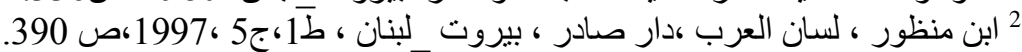

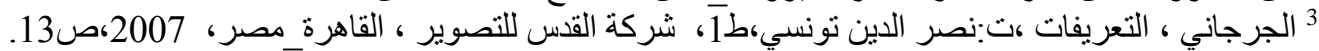

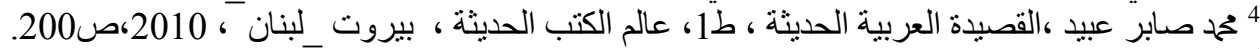

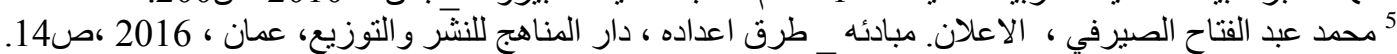

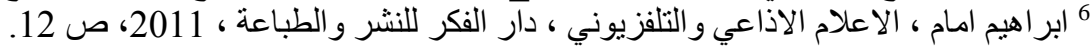




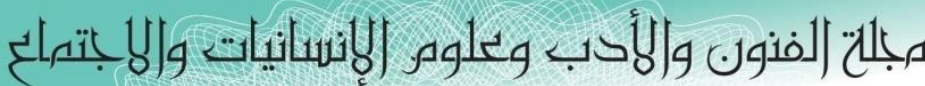

Journal of Arts, Literature, Humanities and Social Sciences

ISSN online: 2414 - 3383

ISSN print: 2616 - 3810

\section{العدد (42) أيلول - سبتمبر 2019}

الاسو اق من خلال تز ايد حاجيات ورغبات الافر اد المستمرة و المعقدة وجب على المؤسسات ابتكار وسائل تسعى (لئى

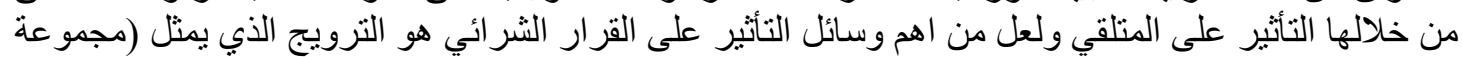

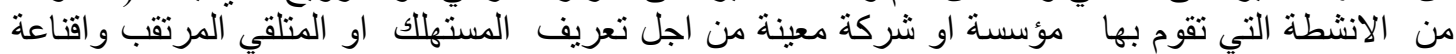

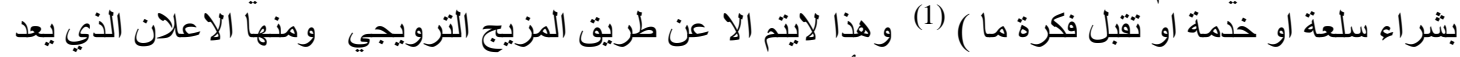

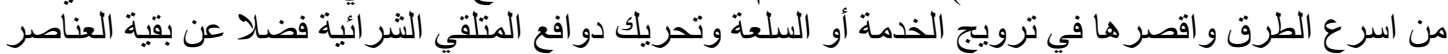

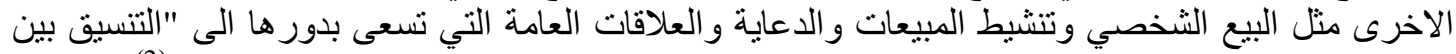

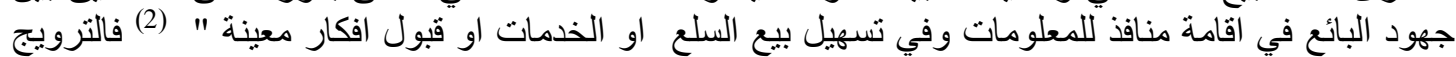

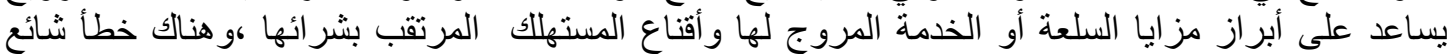

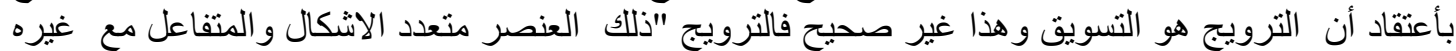

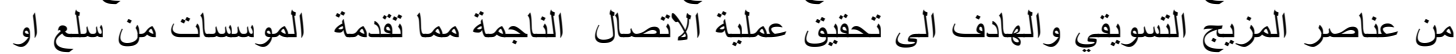

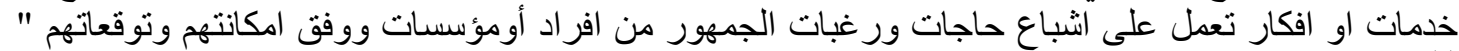

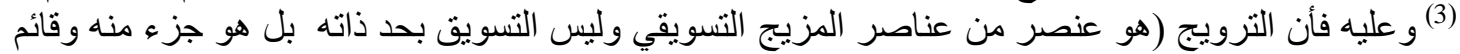

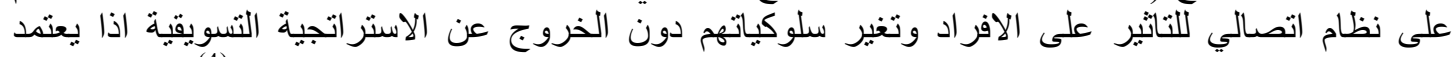

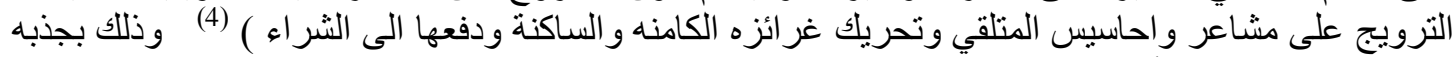

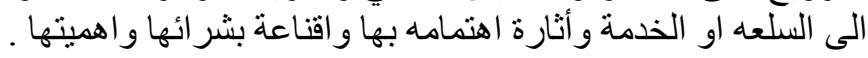

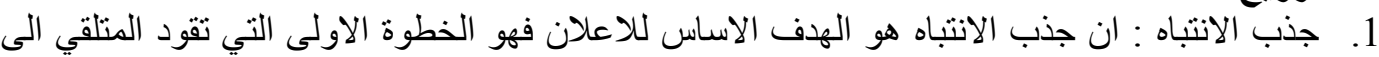

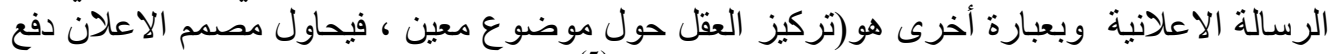

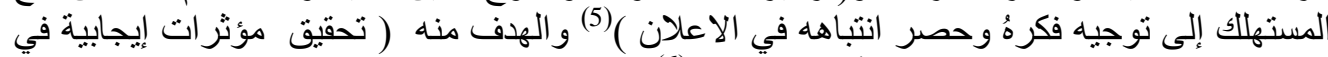

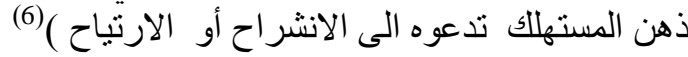

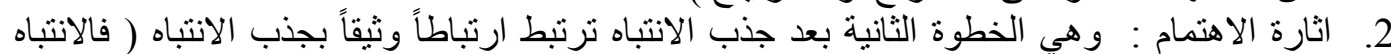

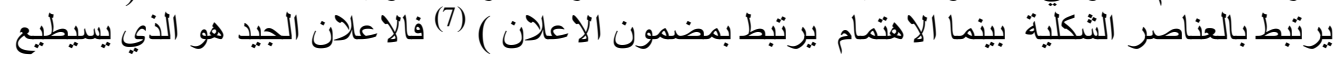

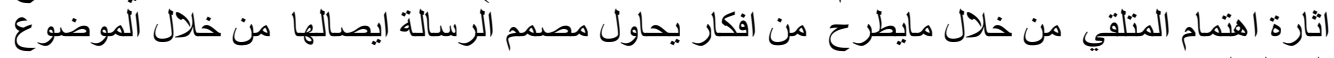

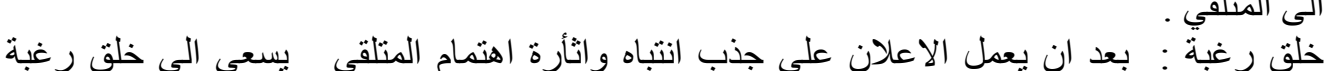

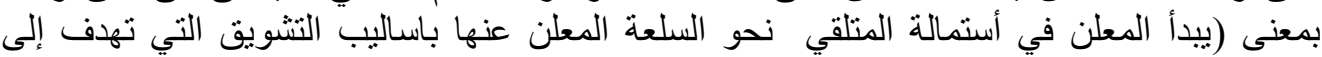

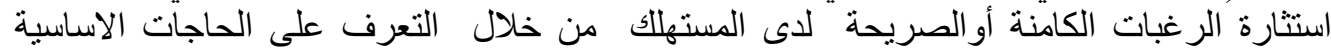

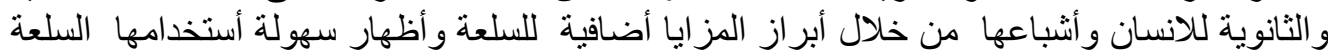

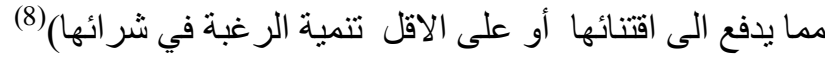

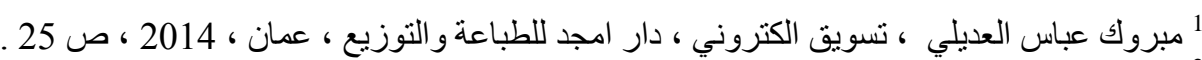

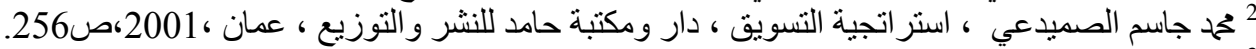

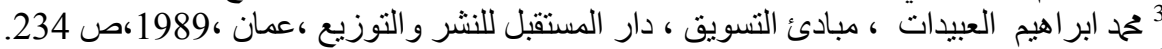

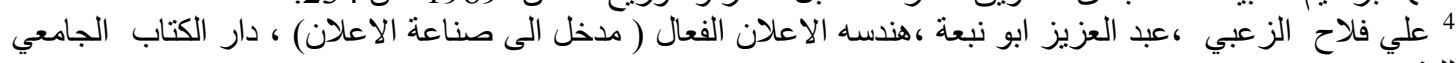

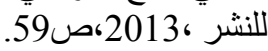
5 ا منى سعيد الحديدي ، سلوى إمام على، الاعلان أسسه وسائله وفنونه ،ط3 ، الدار المصرية اللبنانية ، القاهرة ، 2005،

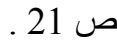

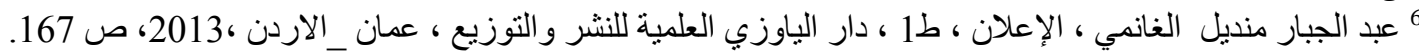

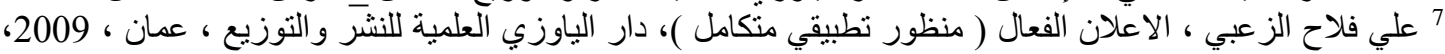




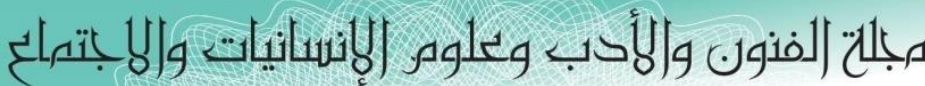

Journal of Arts, Literature, Humanities and Social Sciences

ISSN online: 2414 - 3383

ISSN print: 2616 - 3810

\section{العدد (42) ايلول - سبتهبر 2019}

4. الاقناع : من الوظائف الرئيسة للترويج ويعرف بأنها(علية تحويل او تطويع افكار وآراء ومفاهيم

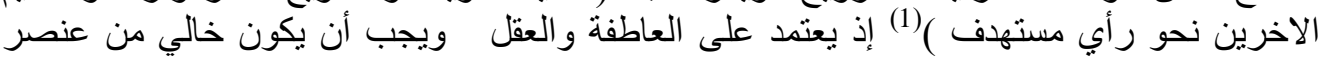

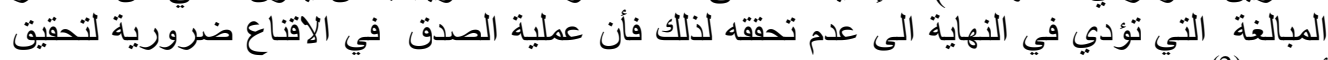
أهدافه (2) المبالغة

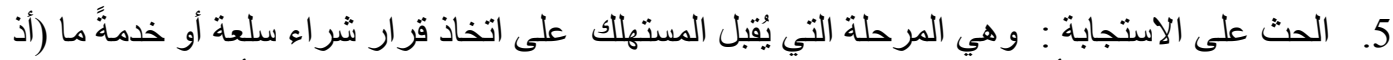

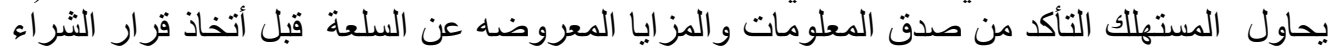

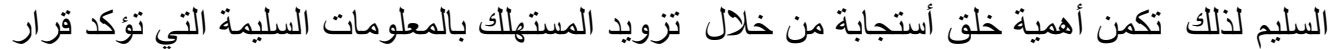

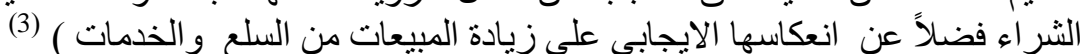

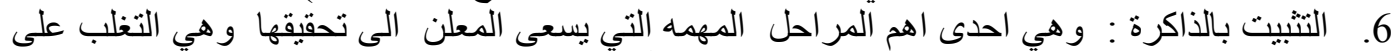

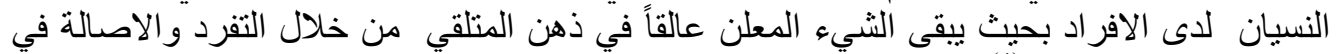

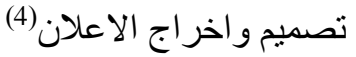

العوامل المساعدة في احداث الاثر اعلاني الترويجي

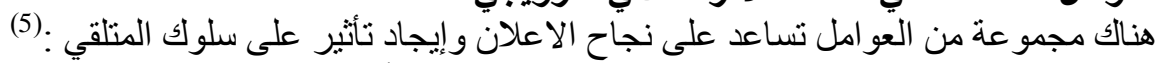
1. النكرار:ويقصد به قراءة الاعلان و الاستماع إليه أكثر من مرة من قبل المستنهلكين المستهافين ويحقق

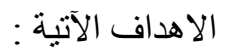

أ. يثبت رسالة الاعلان في ذهن المستهلكة ( تخزين معلومات الاعلان افي لذاكرة)

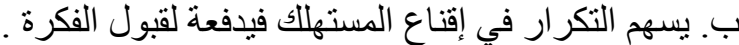

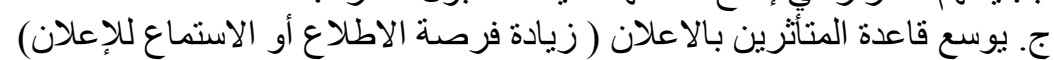

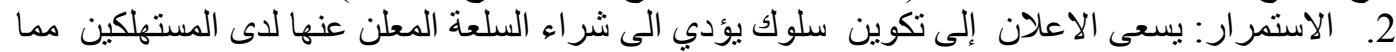

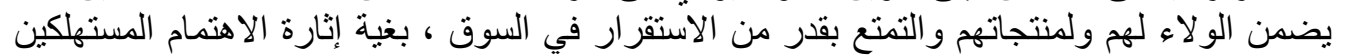

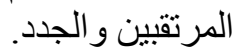
3. الوقت : ويقصد به إتاحة الفرصة الزمنية الكافية لعرض الاعلان بالقدر المحقق لآمال المعلن . الأساليب الترويج المستخدمة في الرسالة الإنعالانية :-

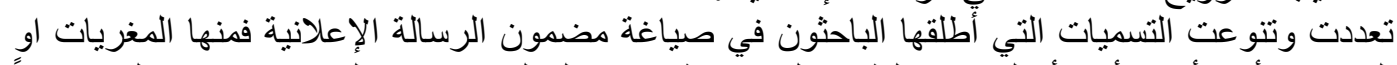

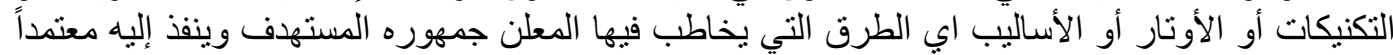

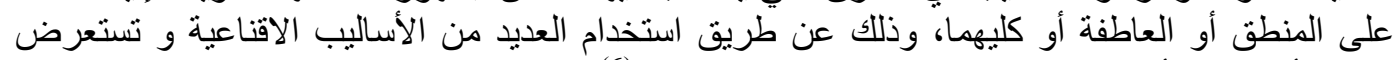

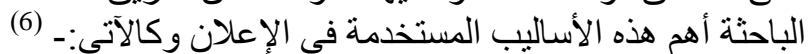

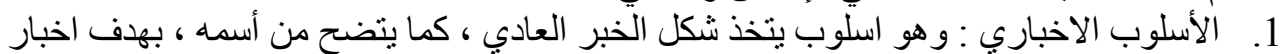

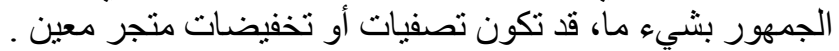

1 إياد حسين عبداله ، فن التصميم ( الفلسفة ، النظرية، التطبيق ) ،ط1، ج1، دائرة الثقافة والاعلام للنشر ، الثارقة

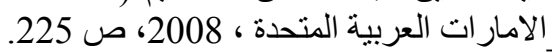
2 ${ }^{2}$

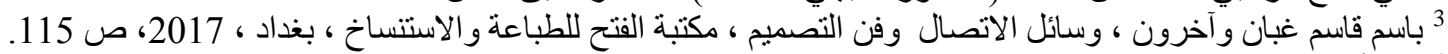

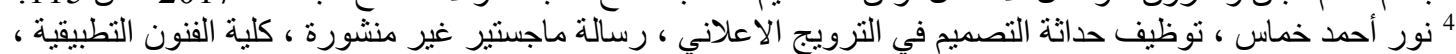

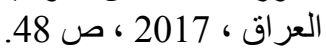
5 علي فلاح الزعبي ، إدريس عبد علد الجواد الحبوني ، إدارة الترويج والإعلان التجاري _ مدخل معاصر ، ط1 ، دار

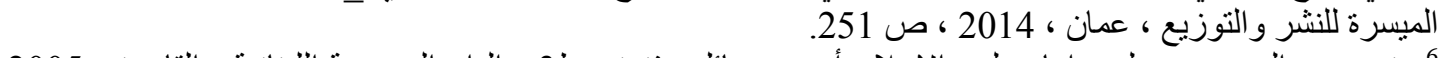
6 منى سعيد الحديدي ، سلوى إمام على، الاعلان أسسه وسائله وفنونه ،ط3 ، الدار المصرية اللبنانية ، القاهرة ، 2005،

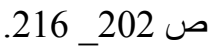




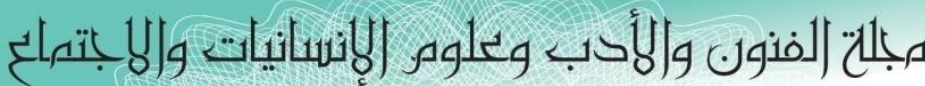

Journal of Arts, Literature, Humanities and Social Sciences

ISSN online: 2414 - 3383

ISSN print: 2616 - 3810

\section{العدد (42) أيلول - سبتمبر 2019}

2. أسلوب الحوار أو الديالوج : يركز على حوار بين شخصين أو أكثر حول السلعة ومميزاتها

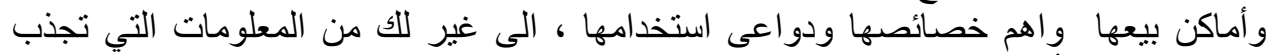

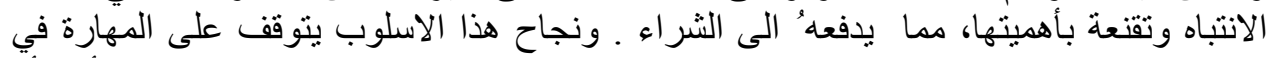

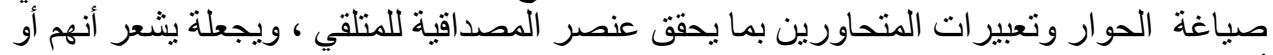

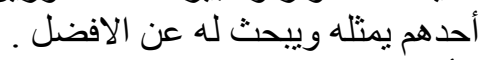

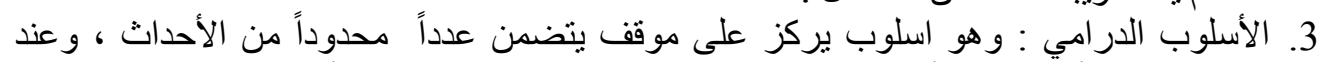

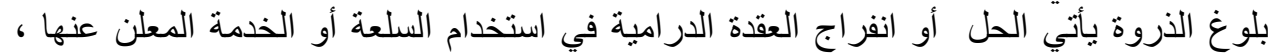

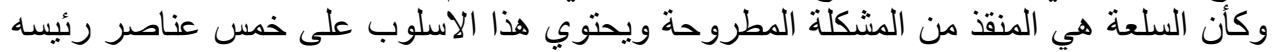

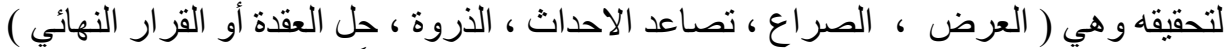
4. أسلوب المشكلة والحل : وهو يأخذ شكل الأسلوب الدرامي تماماً ، ولكن تصميمه أكثر بساطة الأنة و هو بأخذ شكلين :

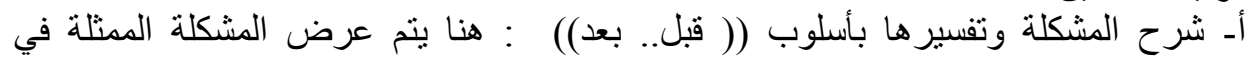

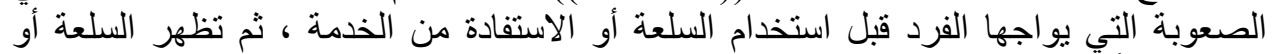

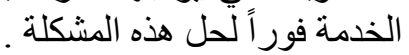

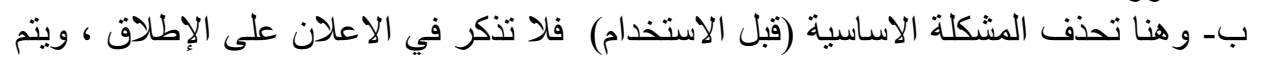
التركيز مباشرة على مز ايا الاستخدام وفو ائدهُ.



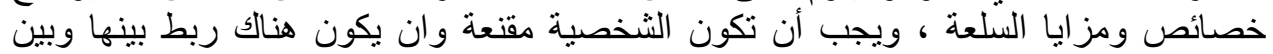

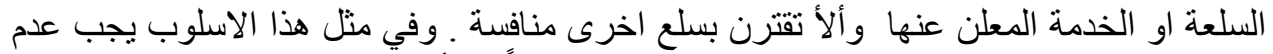

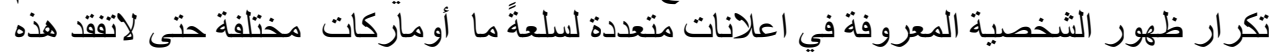

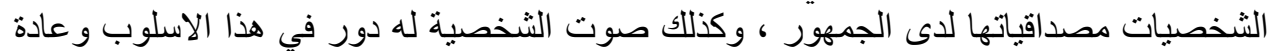

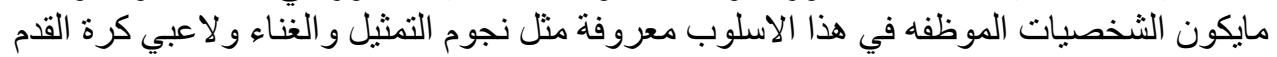

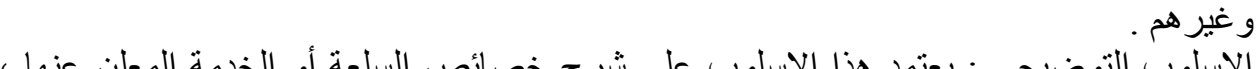

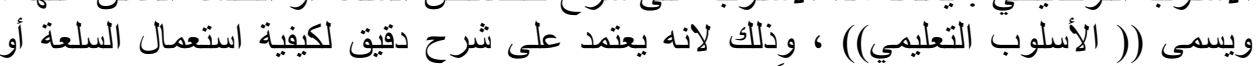

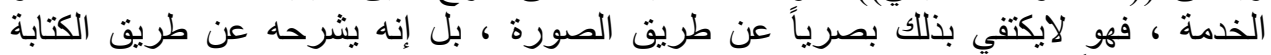

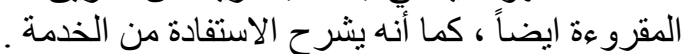

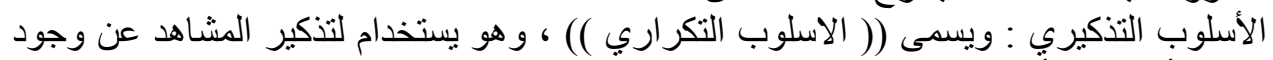

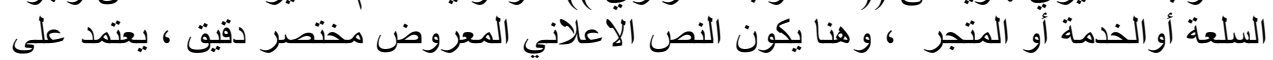

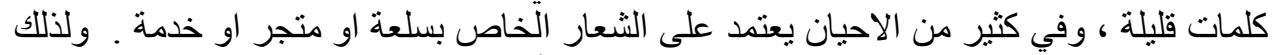

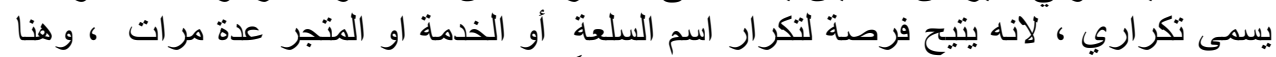

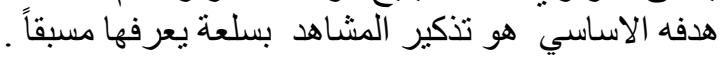

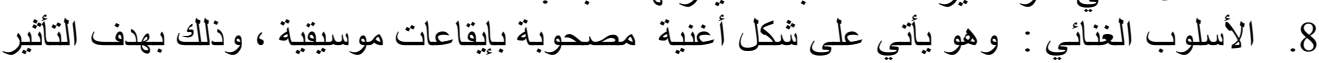

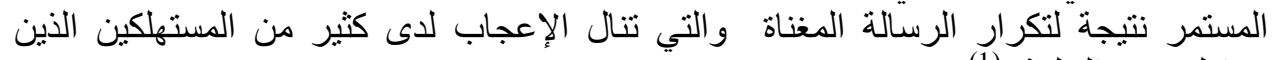

(1) بتعاملون مع السلعة نتئكة 8 


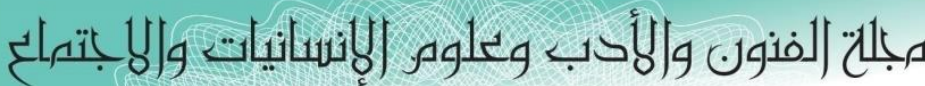

Journal of Arts, Literature, Humanities and Social Sciences

ISSN online: 2414 - 3383

ISSN print: 2616 - 3810

\section{العدد (42) أيلول - سبتمبر 2019}

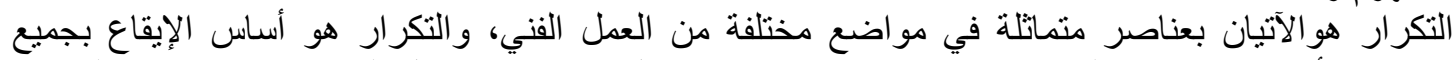

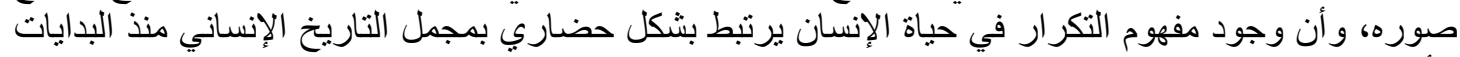

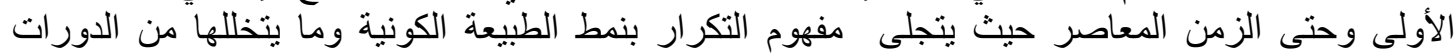
المتعاقبة والمتكررة على مر العصور وحتى الان ، اما التكرار بوجه خاص في فن الاعلان بتمثل بعملية

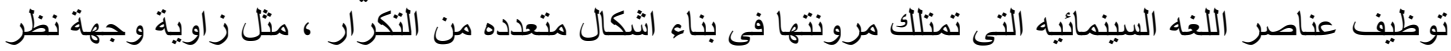



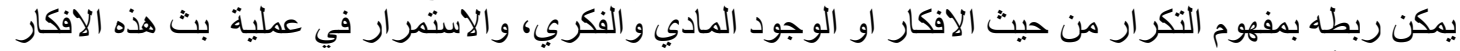

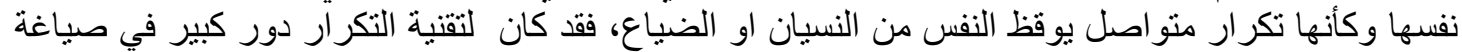
وبناء افكار اعلانية عدة من خلال استخدام أسلوب سردي يعتمد على تكرار جزء معني معين من الاعلان او او جملة

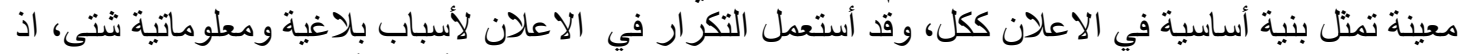

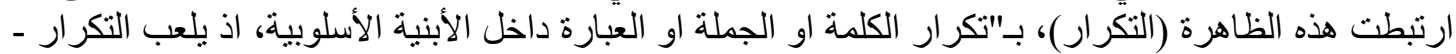

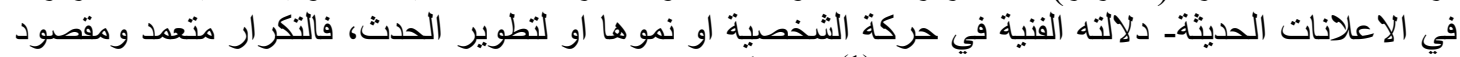
لانهـ نتيجة توظيف التعبير المناسب والَّلانئم"(1) من أجل الاستحو اذ على دلى حواس الانسان وملكاته ، فتتم عملية عرض الاعلان ذهنيا بشكل متسلسل حتى النهاية ،حيث تعمد الاعلانات التلفزيونية على عنصرين اساسيين هما

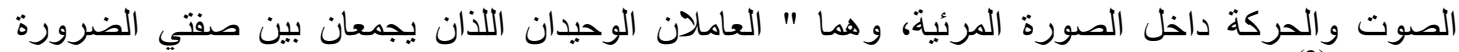

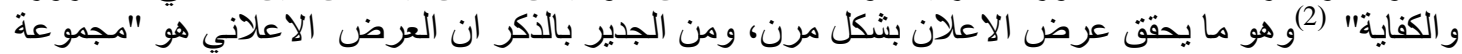

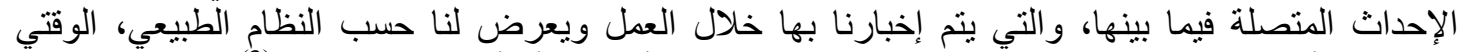

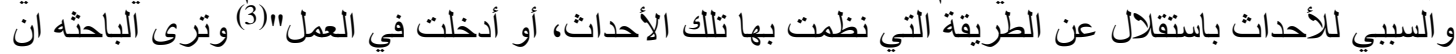

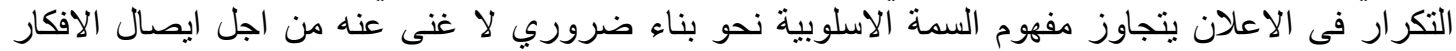

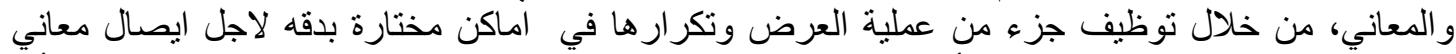

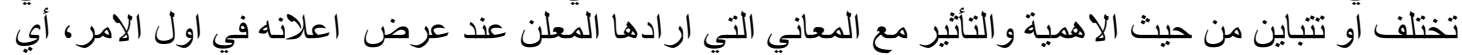

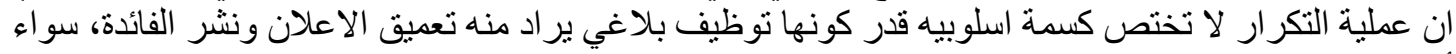

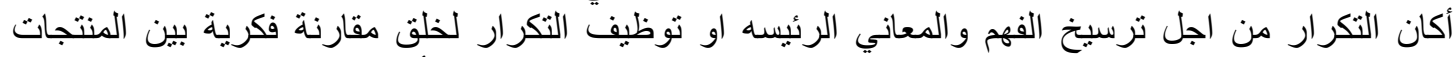

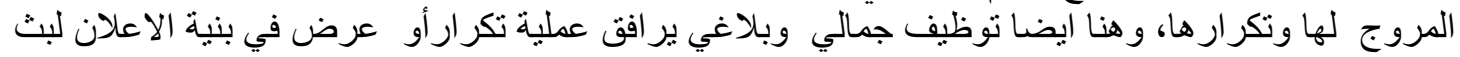

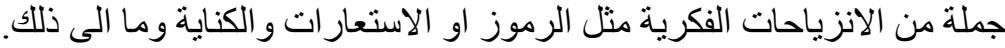

1. التكر ار الموزع : ويقصد به هو التوزيع المناسب على الفترات الزمنية و الذي من شأنه أن يؤدي إلى التي

انواع التكرار

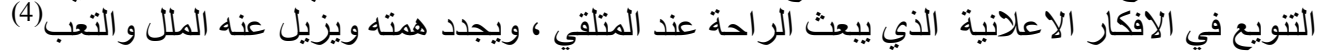

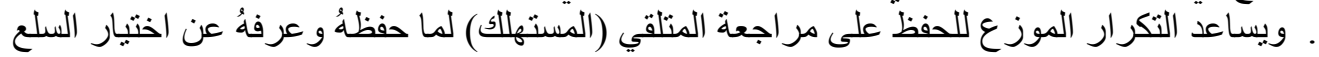

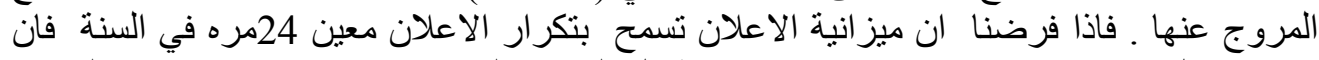
من الافضل ان يتكرار الاعلان مرتين شهريا طوان السنة على ميز ان بتكرار 8مر ات شهريا لمدة 3

1 مجدي العفيفي، الاسس الفنية لتطور القصة القصيرة ، الهيئة العامة المصرية للكتاب للنشر والتوزيع ، القاهرة ،1982، ص مارسي 370. 22 مارسيل مارنن، اللغة السينمائية، ترجمة سعد مكاوي، المؤسسة المصرية العامة للتأليف والإنباء و النشر، القاهرة ،

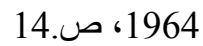

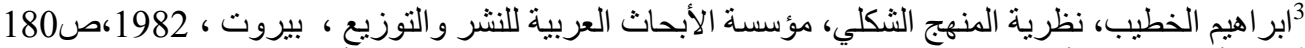

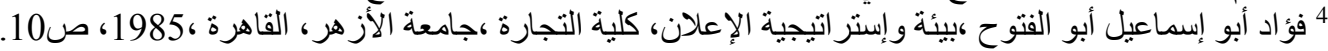




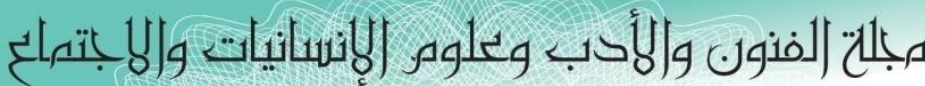

Journal of Arts, Literature, Humanities and Social Sciences

ISSN online: 2414 - 3383

ISSN print: 2616 - 3810

\section{العدد (42) أيلول - سبتمبر 2019}

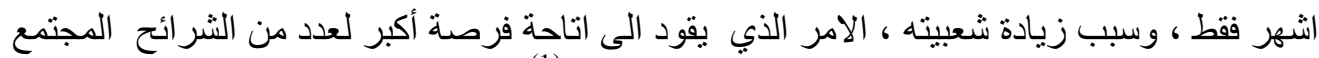

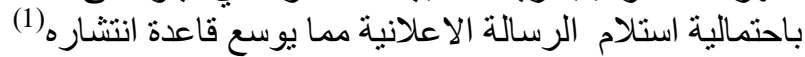

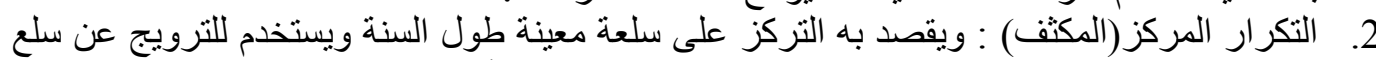

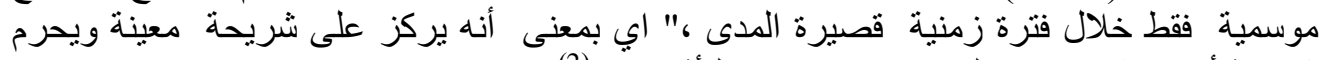

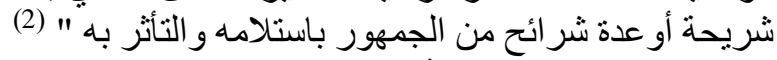

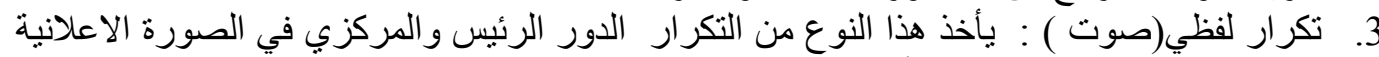

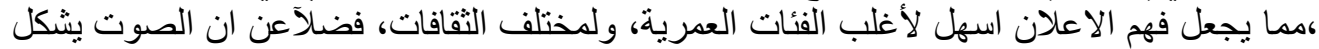

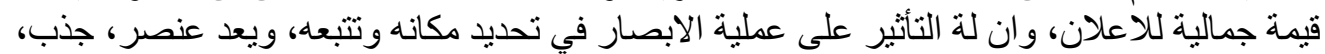

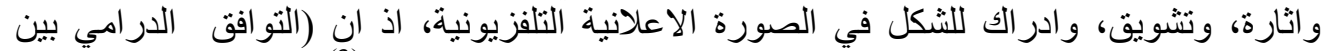

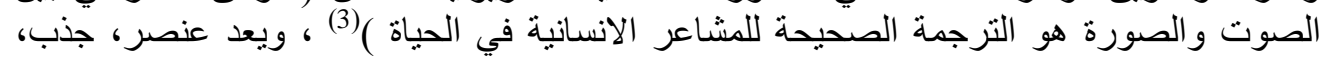

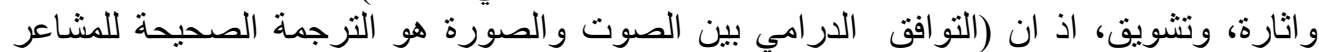

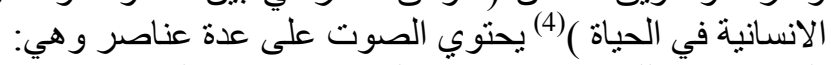

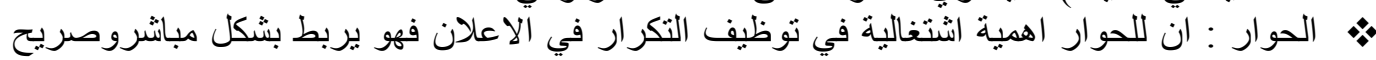

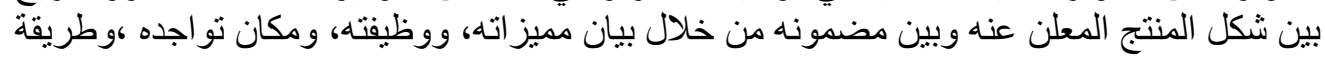

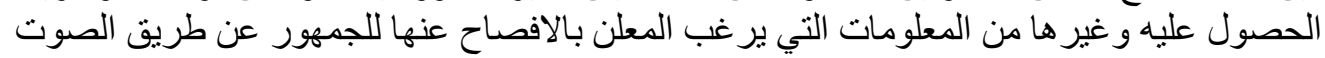

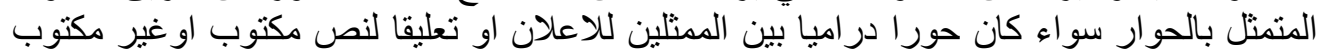

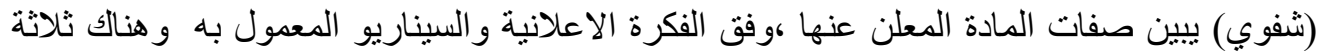

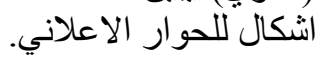

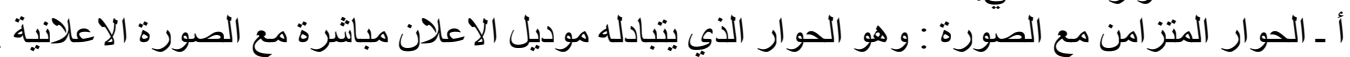

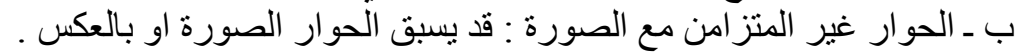

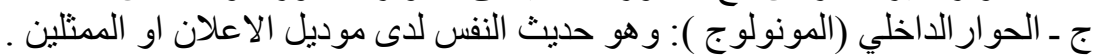

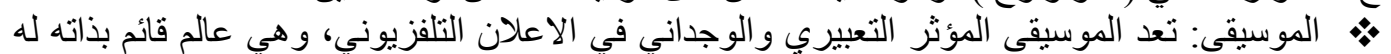

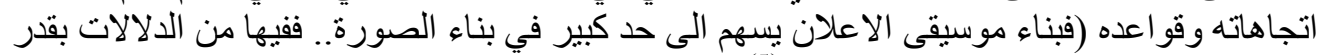

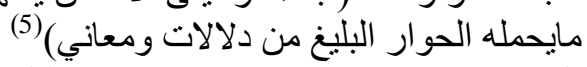

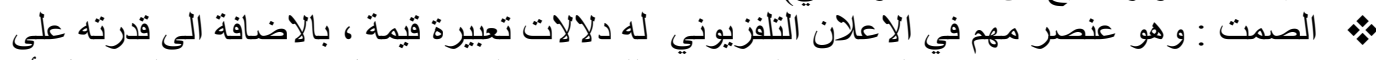

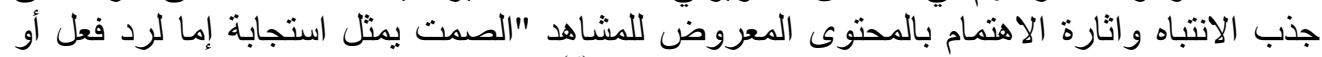

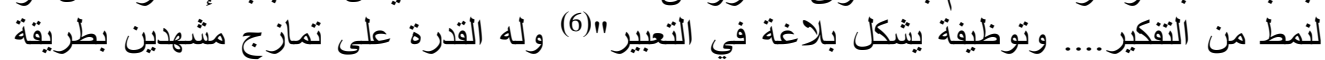

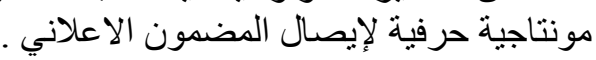

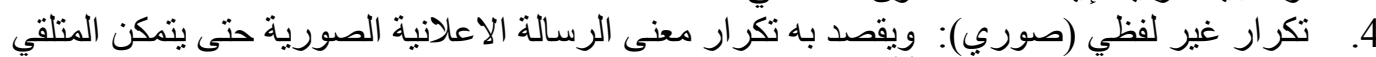

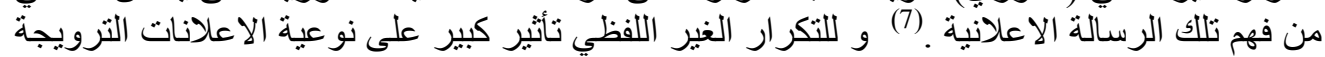

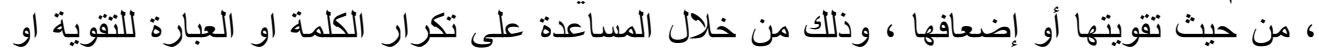

1 بشير عباس العلاق ، علي محمد ربابعة ، الترويج و الاعلان التجاري _مدخل متكامل، دار الباوزي العلمية للنشر والتوزيع

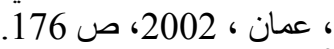

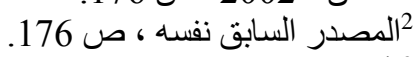

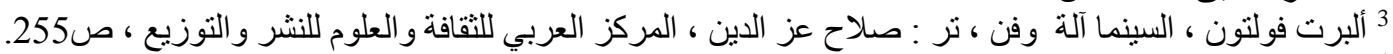

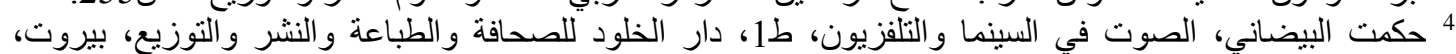

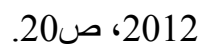

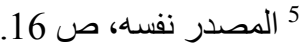
6 حكمت البيضاني ، التوظيف التقني و الجمالي للصوت فئوت في بناء الصورة الفلمية ، سينما 2، اصدار ات دار الثؤون الثقافية

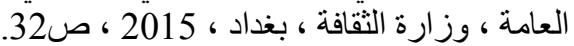
7 فؤاد أبو إسماعيل أبو الفتوح ،بيئة و إستر اتيجية الإعلان، كلية التجارة ،جامعة الأزهر، القاهرة ،1985، ص10. 


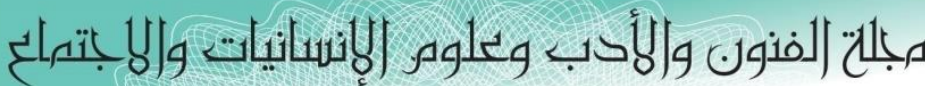

Journal of Arts, Literature, Humanities and Social Sciences

ISSN online: 2414 - 3383

ISSN print: 2616 - 3810

\section{العدد (42) ايلول - سبتهبر 2019}

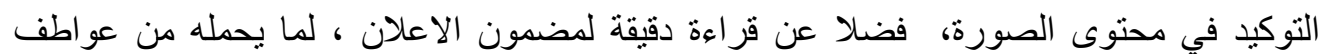

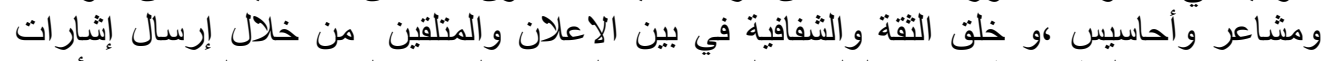

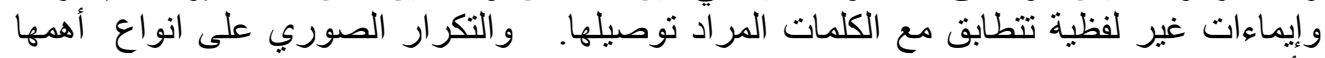

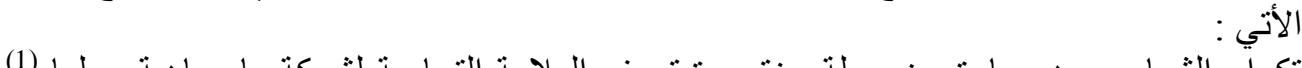
1. تكرار الثعار: و وهو عبارة عن جملة مختصرة تصف العلامة التجارية لثركة ما وماهية عملها (1).

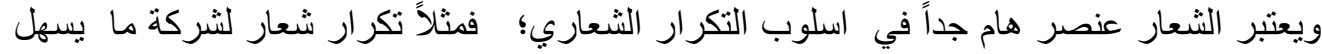

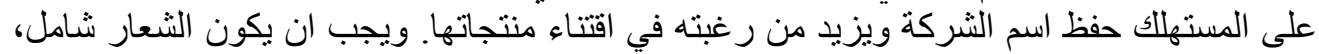

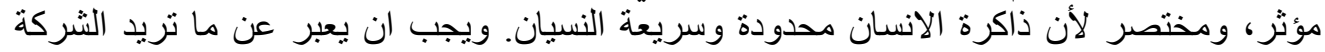

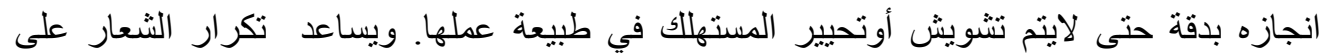


قصبرة يسهل ترديدها من قبل المتلفي.

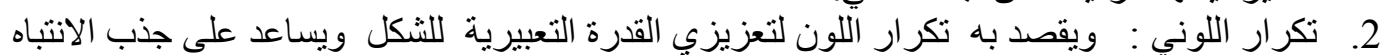

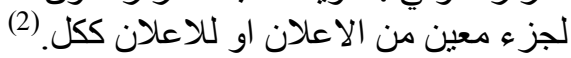
وظائف التكرار

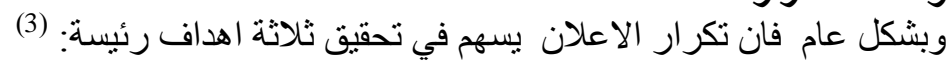

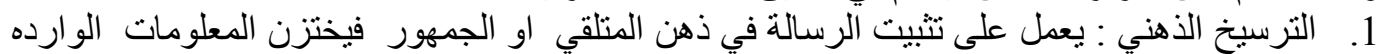

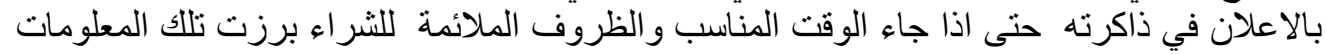

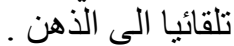
2. تنوع الافكار و التقبل : ان التكرار يساهم في الالحاح على المشاهد او المستمع او القارى الى ان يدفعة

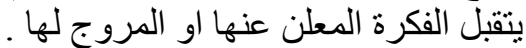

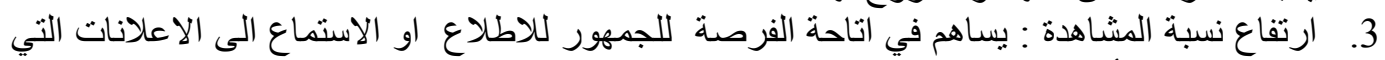

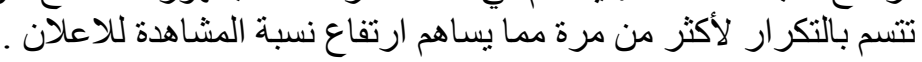

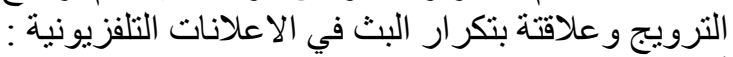

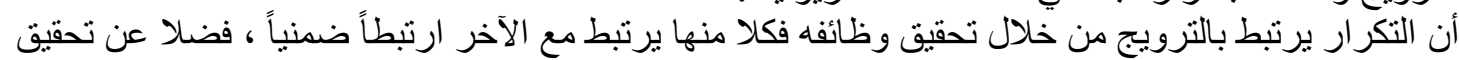

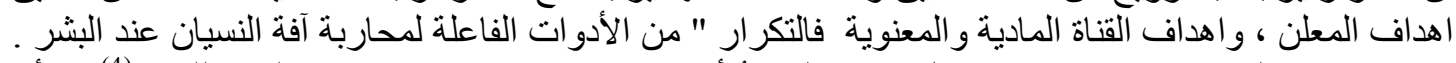

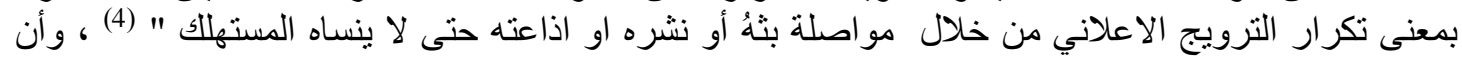

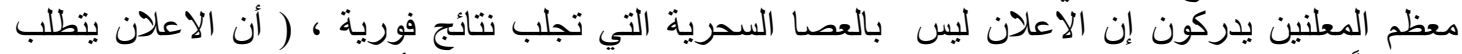

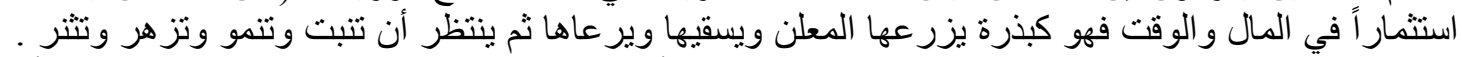

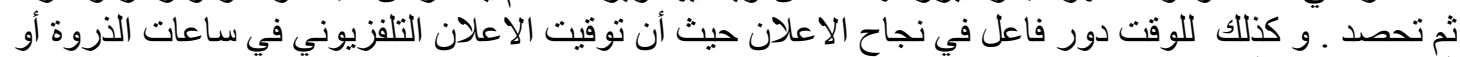

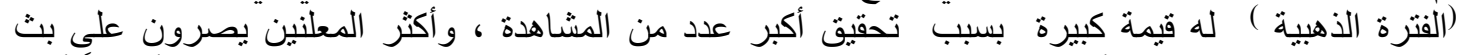

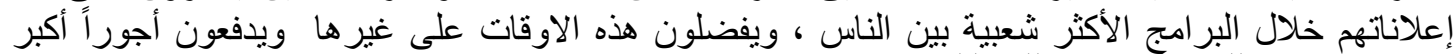

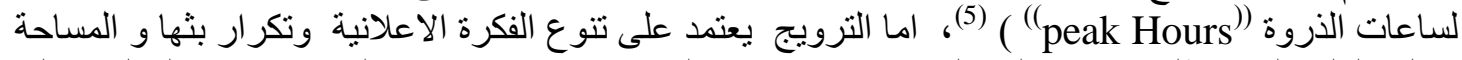

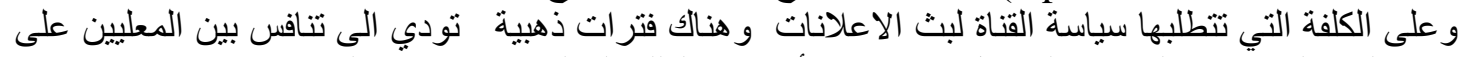

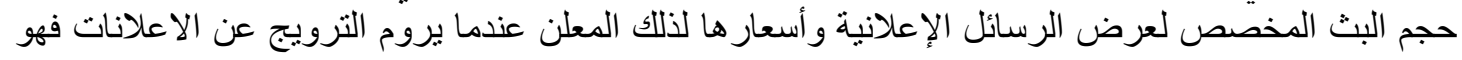

1 1 بشير عباس العلاق ، الابداع والابتكارية في الاعلان ، دذخل تطبيقي ، دار الياوزي للنشر والتوزيع ، 2010، ص

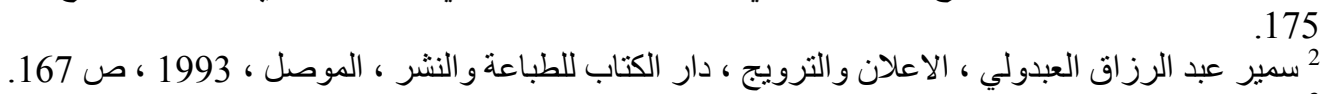

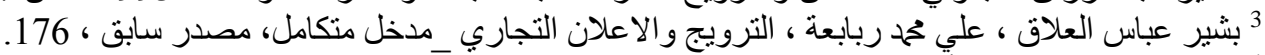

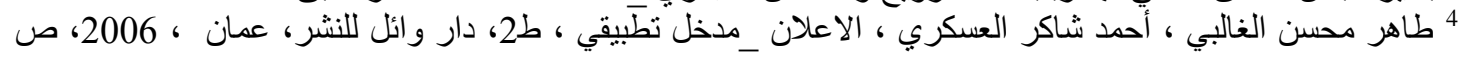

5 طاهر محسن الغالبي ، أحمد شاكر العكري ، الاعلان__مخل تطبيقي ، مصدر سابق ، ص 142_143. 


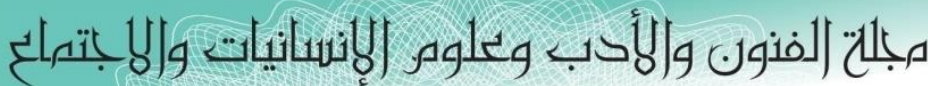

Journal of Arts, Literature, Humanities and Social Sciences

ISSN online: 2414 - 3383

ISSN print: 2616 - 3810

\section{العدد (42) ايلول - سبتهبر 2019}

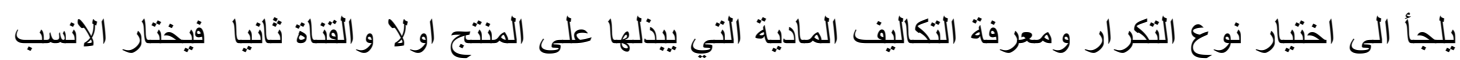

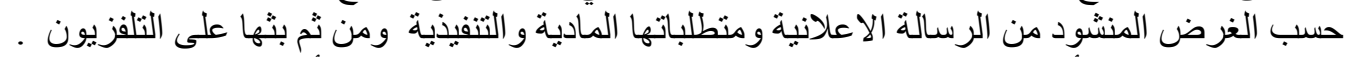

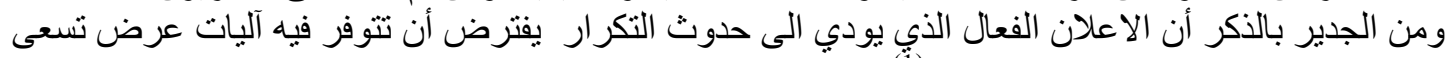

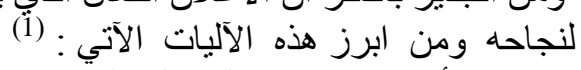

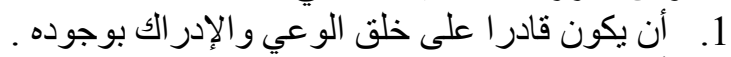
2. 3.

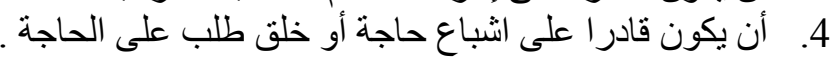

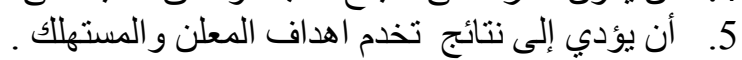

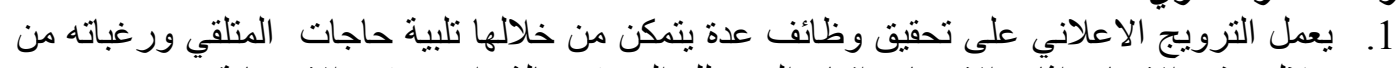

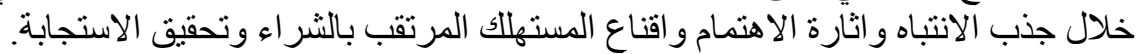

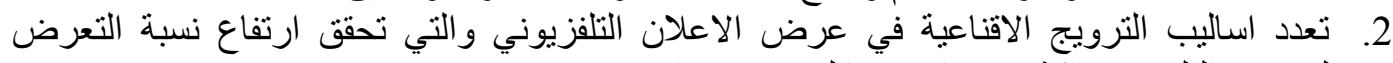

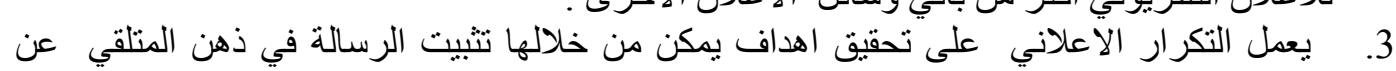

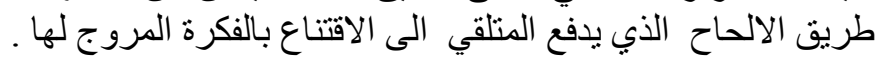

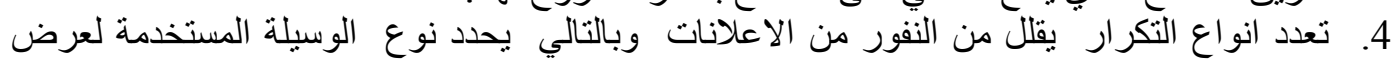

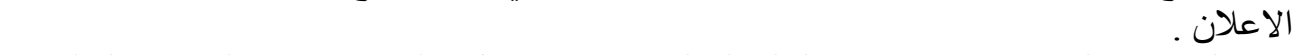

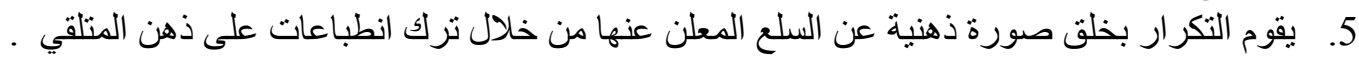

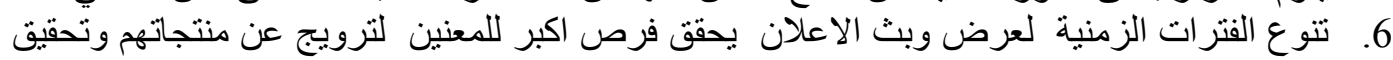

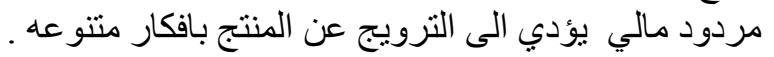

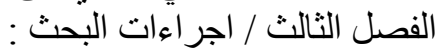

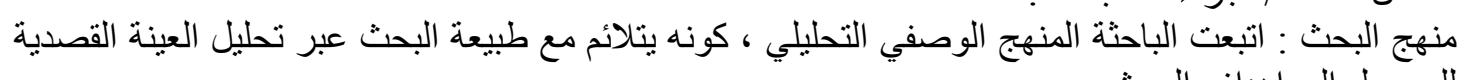

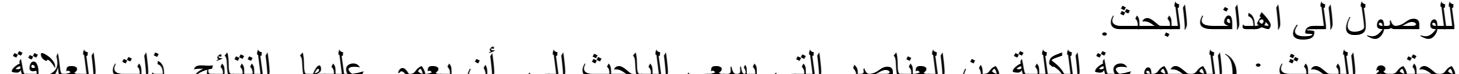



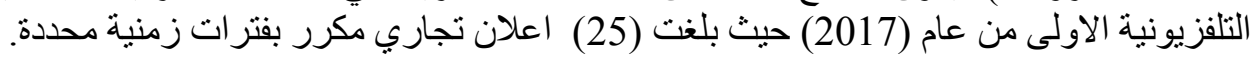

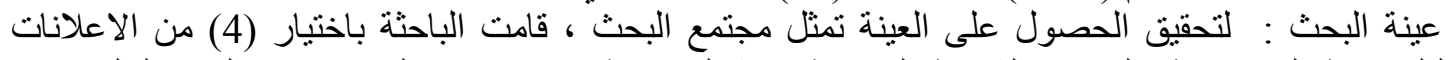

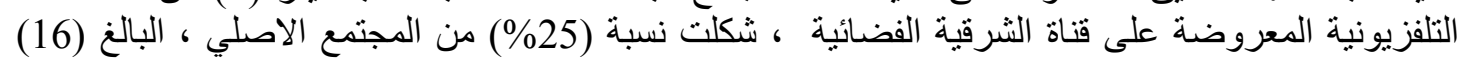

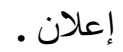

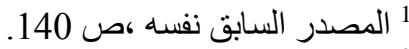

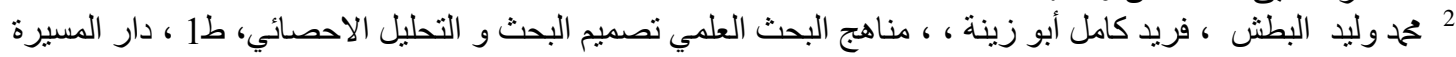

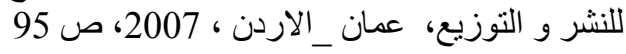




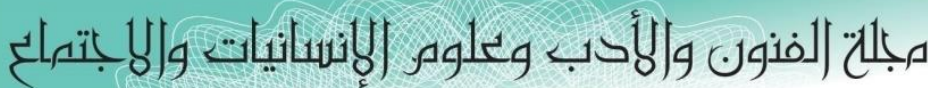

Journal of Arts, Literature, Humanities and Social Sciences

ISSN online: 2414 - 3383

ISSN print: 2616 - 3810

العدد (42) ايلول -سبتهبر 2019

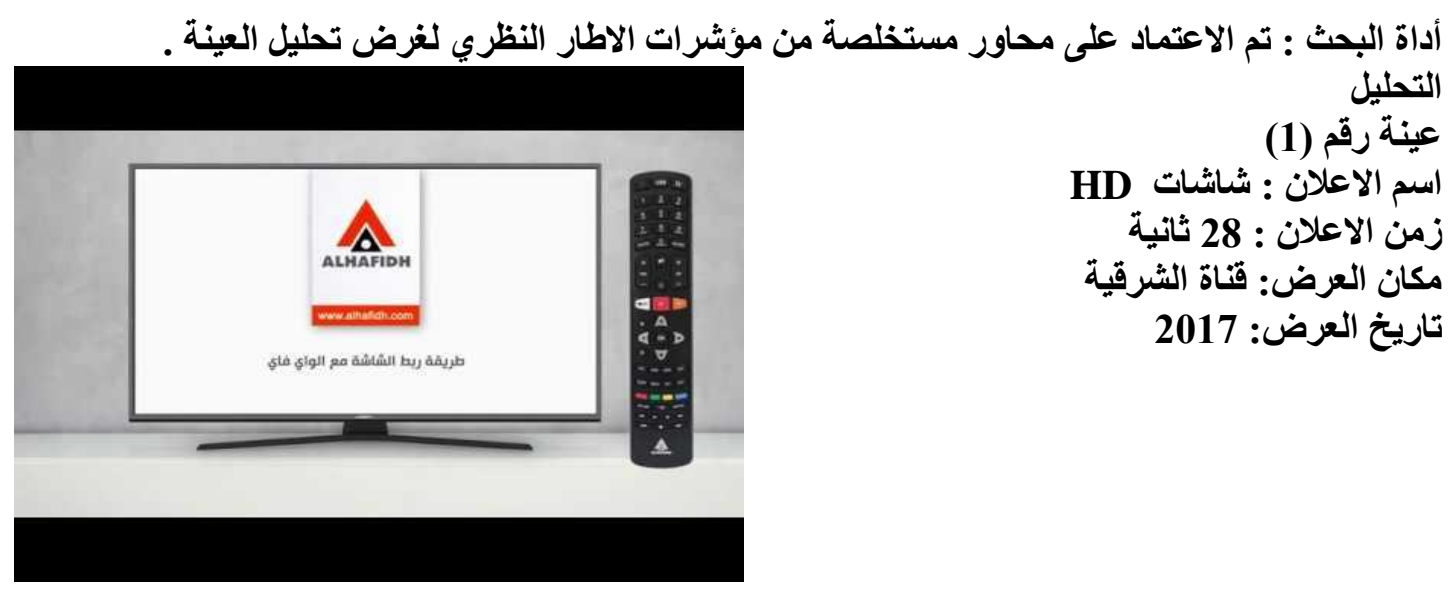

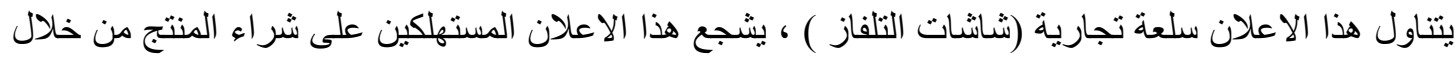

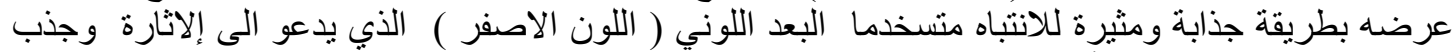

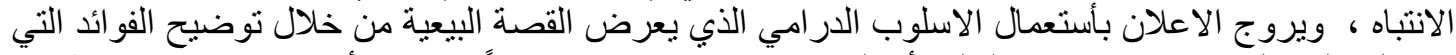

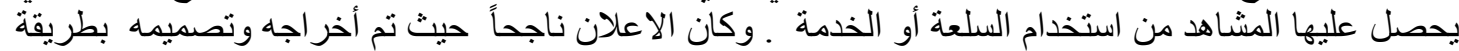

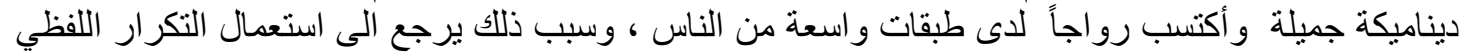

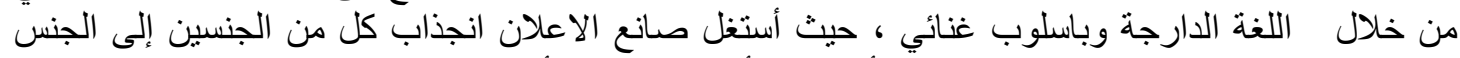

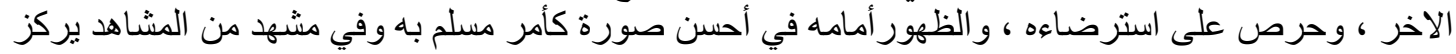

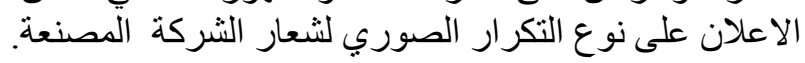

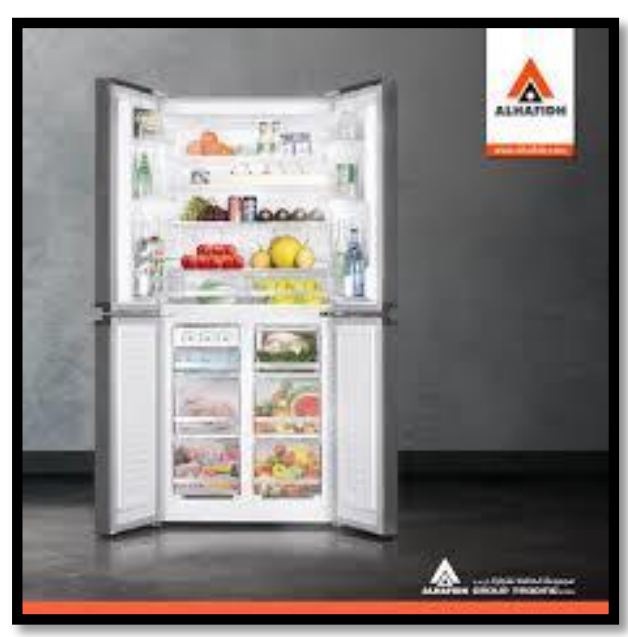

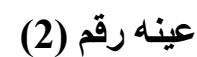
استم الاعلان : ثُلاجات الحافظ


مكان العرض: قالعاة الثرقية

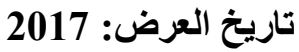

يتناول هذا الاعلان سلعة تجارية وهي ( ثلاجات الحافظ )

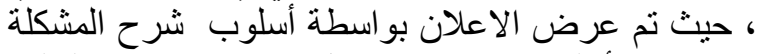

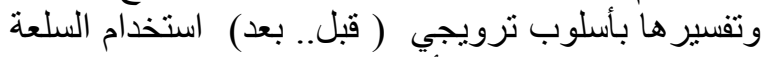

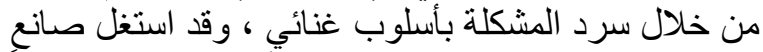

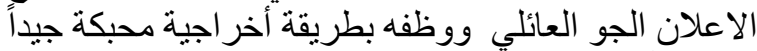



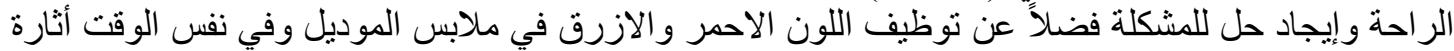

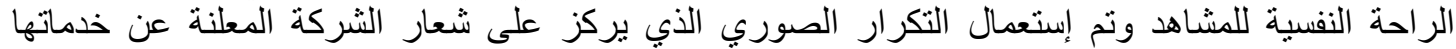

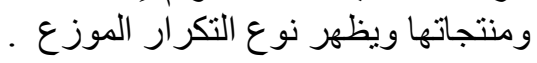




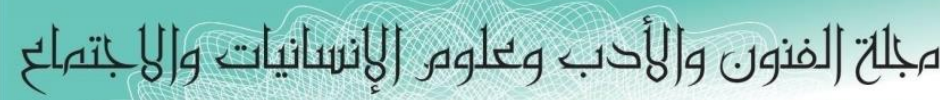
Journal of Arts, Literature, Humanities and Social Sciences

ISSN online: 2414 - 3383

ISSN print: 2616 - 3810

\section{العدد (42) أيلول - سبتمبر 2019}

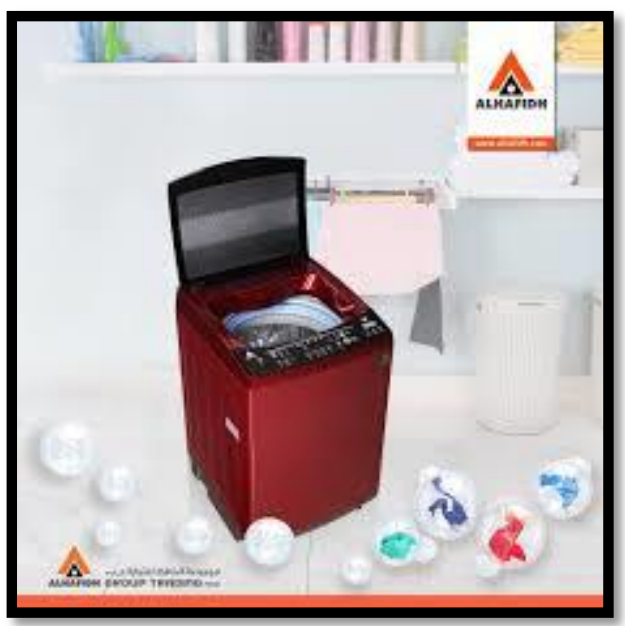

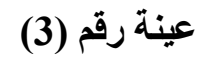

اسم الاعلان : غسالات الحافظ

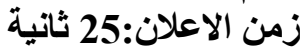

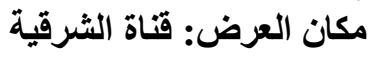
تاريخ العرض: ( 2017)

يعرض هذا الاعلان سلعة تجارية ( غسالة الحافظ

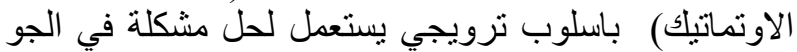

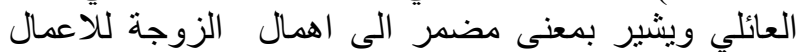

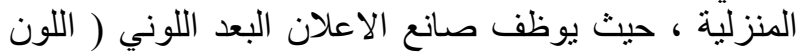

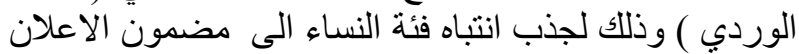

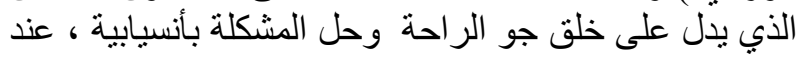

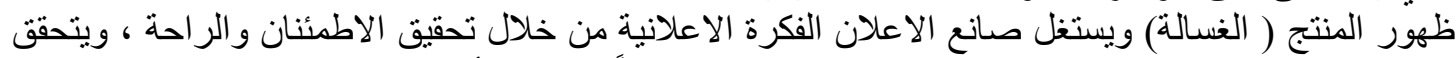

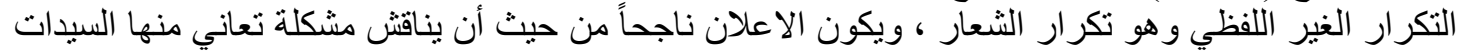

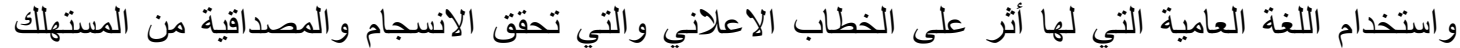

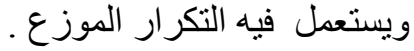

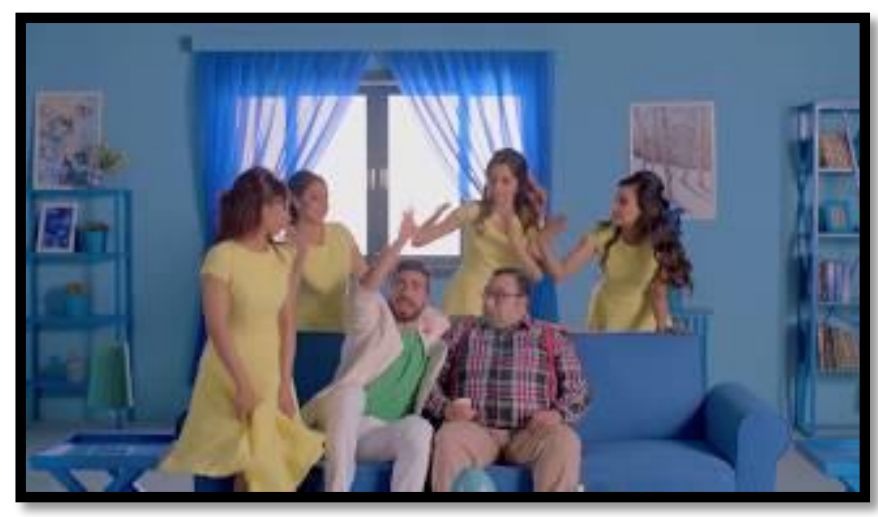

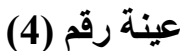
اسم الاعلان : سبلت الحافظ .

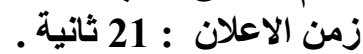

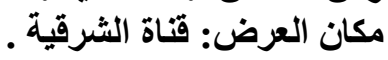

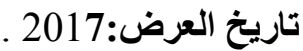

يعرض هذا الاعلان باسلوب ترويجي

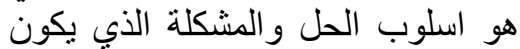

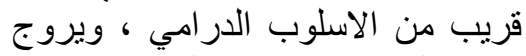

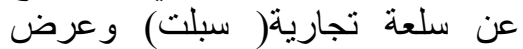

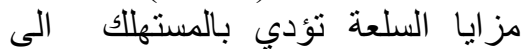

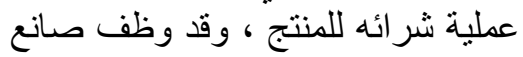

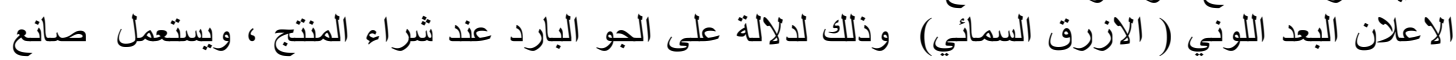

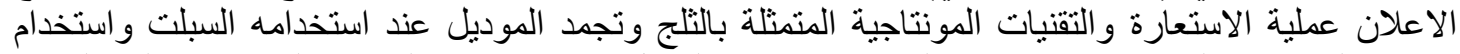

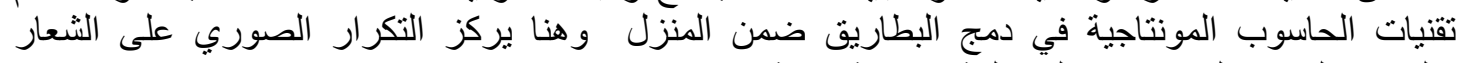
و التكر ار المركز الذي يركز على سلعة موسمية معينة . لفئل

توصل البحث الى النتائج الاتية: 1. اعتمد الفعل الدرامي للاعلان في تحقق الاقناع على الدور التعبيريري للعناصر السمعية والمرئية

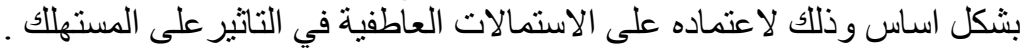




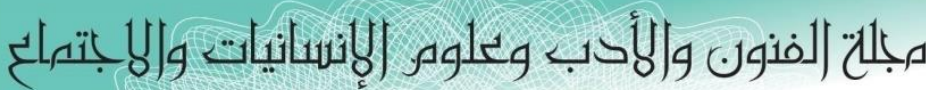

Journal of Arts, Literature, Humanities and Social Sciences

ISSN online: 2414 - 3383

ISSN print: 2616 - 3810

\section{العدد (42) أيلول - سبتمبر 2019}

2. إن الإعلانات (عينات البحث) التي تم عرضه ثلاث مر ات في فترة زمنية وجيزة لا تتعدي الـ 25

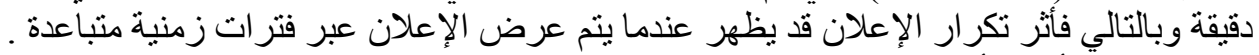

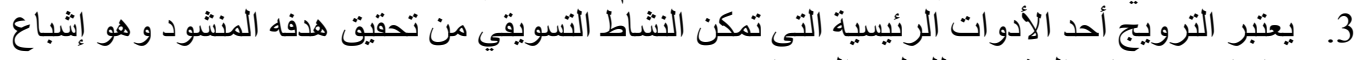

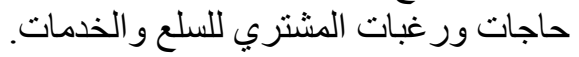

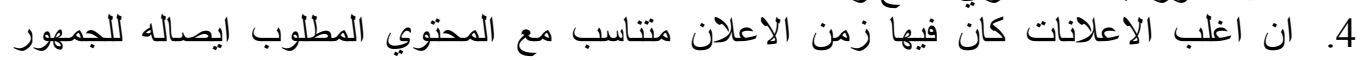

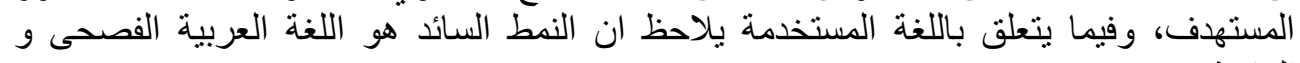

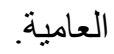

الاستنتاجات

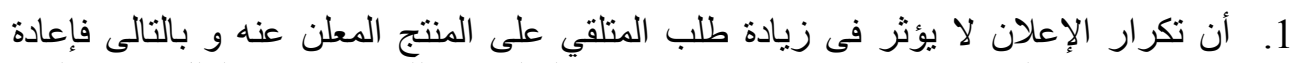

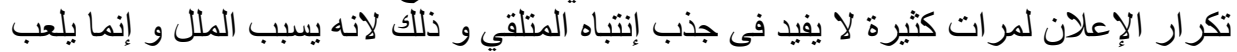
دور اتذكيريا فقط.



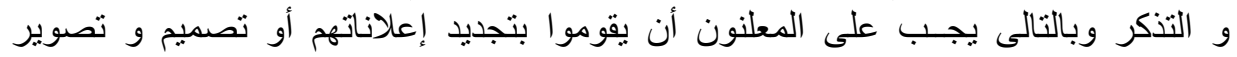

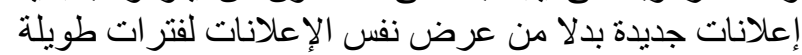

3. تسخير تقنيات التصوير و الصوض علإن لإثارة الاهنمام بالموديل الظاهر في الترويج الاعلاني .

ضرورة ان تقوم الجهات الانتاجية بدراسة الجمهور المتلقي سواء للخطاب المرئي الدرامي او غير

التوصيات

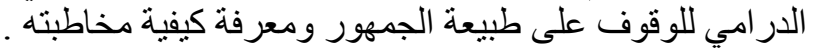

1. توظيف التقنيات المونتاجية في التكرار الاعلاني (دراسة تحليلية) .

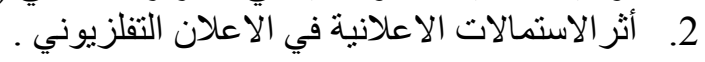

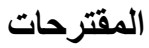

المصادر

1. ابراهيم الخطيب، نظرية المنهج الثكلي، مؤسسة الأبحاث العربية للنشر والتوزيع ، بيروت ،

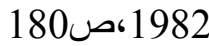

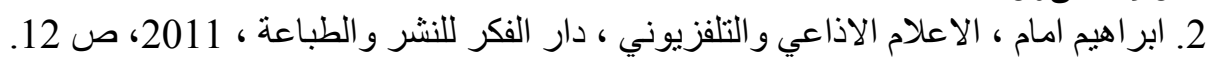

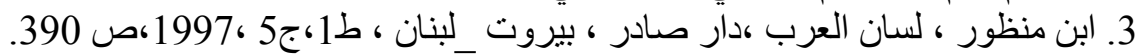

4. ألبرت فولتون ، السينما آلة وفن ، تز : صلاح عز عز الدين ، المركز العربي للتقافة والعلوم للنشر و التوزيع ،

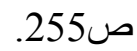

5. اياد حسين عبداله ، فن التصميم ( الفلسفة ، النظرية، التطبيق ) ،ط1، ج1، دائرة الثقافة والاعلام للنشر ،

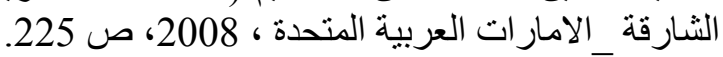

6. باسم قَاسم غبان وآخرون ، وسائل الاتصال وفرك وفن التصميم ، مكتبة الفتح للطباعة والاستنساخ ، بغداد ،

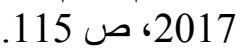

7. بشير عباس العلاق ، الابداع والابنكارية في الاعلان ، مدخل تطبيقي ، دار الباوزي للنشر والتوزيع ،

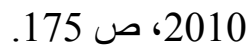
8. بشير عباس العلاق ، علي محمد ربابعة ، الترويج والاعلان التجاري _مدخل متكامل، دار الباوزي العلمية

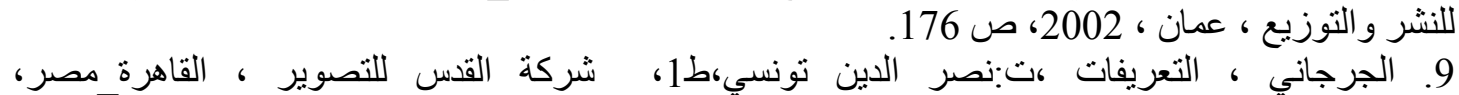

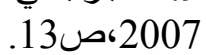
10. جوزيف الياس ، منجد المجاني المصور ، دار المجاني ، ط2،لبنان ،2000،ص387. 


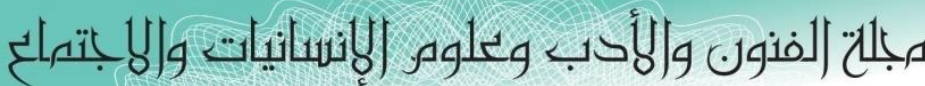

Journal of Arts, Literature, Humanities and Social Sciences

ISSN online: 2414 - 3383

ISSN print: 2616 - 3810

\section{العدد (42) ايلول - سبتهبر 2019}

11. حسام فتحي ابو طعيمة ،الاعلان وسلوك المستهلك بين النظرية والتطبيق ، دار فاروق ،ط1، عمان ، 7502008

12. حكمت البيضاني ، التوظيف التقني و الجمالي للصوت في بناء الصورة الفلمية ، سينما 2، اصدارات دات دار

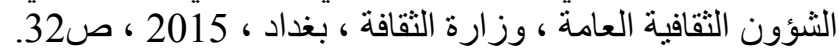

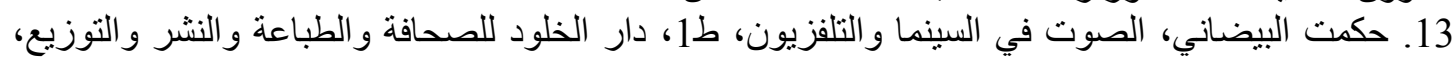


167. سمير عبد الرزاق العبدولي ، الاعلان و الترويج ، دار الكتاب للطباعة والنشر ، الموصل ، 1993 ، ص 167. 14 15. طاهر محسن الغالبي ، أحمد شاكر العسكري ، الاعلان _مدخل تطبيقي ، ط2، دار و ائل للنشر، عمان ،

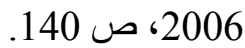
16. عبد الجبار منديل الغانمي ، الإعلان ، ط1 ، دار الياوزي العلمية للنشر و التوزيع ، عمان _الاردن ،2013،

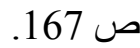

17. عبد الصبور محسن فتحي ، اسرار الترويج في عصر العولمة ، مجموعة النيل العربية ، ط1، القاهرة ، 1502000 18. علي فلاح الزعبي ،عبد العزيز ابو نبعة ،هندسه الاعلان الفعال ( مدخل الى صناعة الاعلان) ، دار

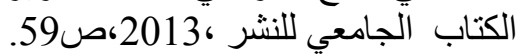

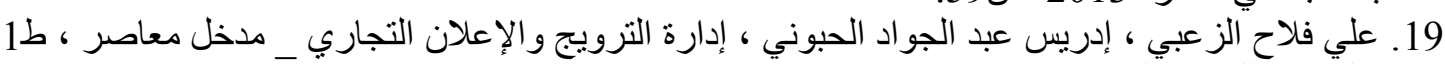

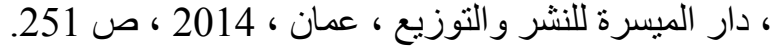
20. علي فلاح الزعبي ، الاعلان الفعال _ منظور تطبيقي متكامل ، ـ دار الياوزي العلمية للنشر والتوزيع ،

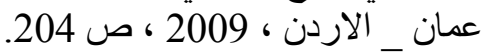
21. فؤاد أبو إسماعيل أبو الفتوح كبيئة و إستراتيجية الإعلان، كلية التجارة ،جامعة الأزهر، القاهرة ،1985،

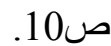
22. مارسيل مارتن، اللغة السينمائية، نرجمة سعد مكاوي، المؤسسة المصرية العامة للتأليف والإنباء والنشر،

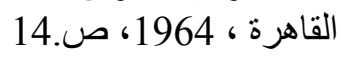

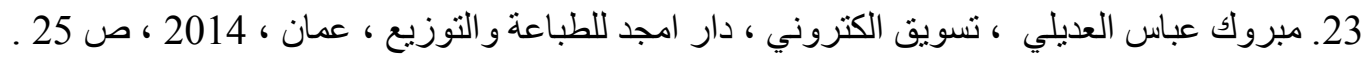

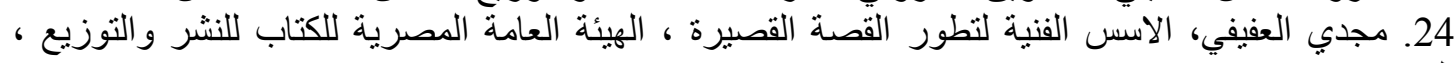

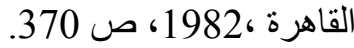

25. محمد ابر اهيم العبيدات ، مبادئ التسويق ، دار المستقبل للنشر و التوزيع ،عمان ،

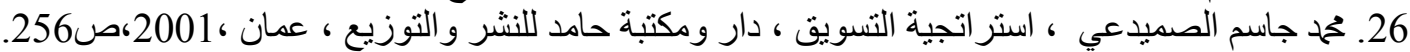

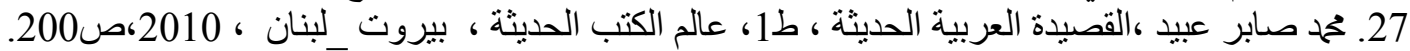

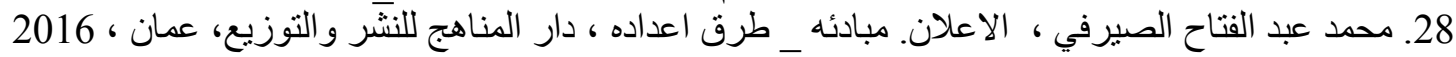
14.

29. تحمد وليد البطش ، فريد كامل أبو زينة ، ، مناهج البحث العلمي تصميم البحث و التحليل الاحصائي، ط1 ،

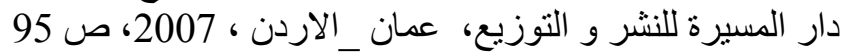

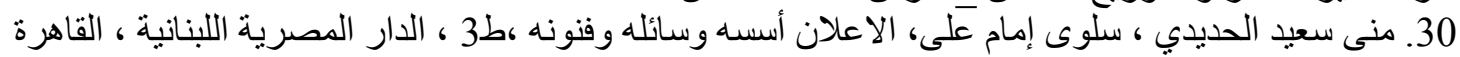

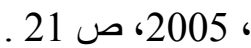

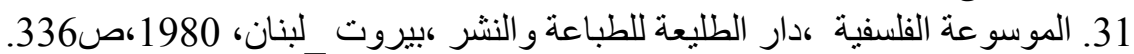

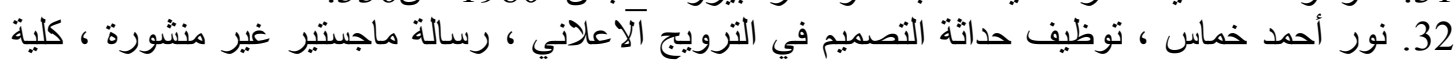

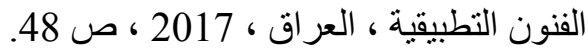

